\title{
Designing Drone Game for Construction Site Inspection
}

\author{
Kenneth Lawani ${ }^{1 *}$, Billy Hare ${ }^{1}$, lain Cameron ${ }^{1}$, Hamid Homatash ${ }^{2}$ and Julie Campbell ${ }^{2}$ \\ ${ }^{1}$ Department of Construction and Surveying, Glasgow Caledonian University, Glasgow, United Kingdom, ${ }^{2}$ Department of Applied \\ Computer Games, Glasgow Caledonian University, Glasgow, United Kingdom
}

OPEN ACCESS

Edited by:

Timothy O. Olawumi,

Edinburgh Napier University, United Kingdom

Reviewed by:

Assed N. Haddad,

Federal University of Rio de Janeiro,

Brazil

Marcela Spišáková Technical University of Košice,

Slovakia

Ayodeji Emmanuel Oke, Federal University of Technology, Nigeria

Narimah Kasim Universiti Tun Hussein Onn Malaysia, Malaysia

*Correspondence: Kenneth Lawani kenneth.lawani@gcu.ac.uk

Specialty section:

This article was submitted to Construction Management, a section of the journal Frontiers in Built Environment

Received: 06 September 2021 Accepted: 17 December 2021

Published: 17 February 2022

Citation:

Lawani K, Hare B, Cameron I, Homatash H and Campbell J (2022)

Designing Drone Game for

Construction Site Inspection.

Front. Built Environ. 7:771703.

doi: 10.3389/fbuil.2021.771703
The use of drone technology in the construction sector promises faster and more streamlined working practices. Forward-thinking contractors are investing in digitizing their operations and the use of drones with the capability of providing real-time site information is already a reality. Deploying drones for site inspections can help construction and safety managers avoid placing workers in precarious situations and the ability to quickly gather site aerial data can be invaluable. This study focuses on creating a drone flying game for inspecting a virtual construction site and identifying potential safety hazards. The single-player, user-focused game is built using the Unity game engine for WebGL which renders interactive 3D graphics to be played in modern web browsers without the use of plug-ins. The game's aim is to give a simulated experience of piloting a drone and using it to identify potential hazards in an active simulated construction site, and educating players of the effectiveness of using drones for this task, without the real-world risk of collision, damage or injury. Preliminary findings from 47 purposive sampled participants revealed that the drone game was engaging; participants found the game intuitive to use and easy to pilot the drone; the hazards and the simulated construction environment were realistic; and the game satisfies the main aim of highlighting the benefits of using drones on a construction site. The target audience for user experience and usability testing are construction and safety managers, construction professionals and students working in the industry. The skills acquired from playing the educational drone game for virtual construction site inspection and monitoring could be successfully applied when flying a real drone on a live construction site. The significance of learning how to fly drones for site inspection during Covid-19 pandemic where workers need to be physically distanced is timely and relevant.

Keywords: drone, site inspection, simulation, game-based, site safety, web graphics library

\section{INTRODUCTION}

The adoption and use of innovative technology to improve construction operations, most significantly health and safety is becoming a norm as it is less expensive and more reliable than before. The use of drone technology in the construction industry has substantial potential in terms of improving safety inspections and construction practices (Xiang et al., 2019; Homann and McAllister, 2018). Workers within the industry are susceptible to accidents which could either be fatal or lead to permanent disablement as the HSE construction statistics in Great Britain for 2020 identified (HSE, 2020). The construction industry plays a significant role in economic growth in all countries. However, workers employed in this industry worldwide tend to experience a disproportionately high 
rate of injuries and fatalities; for example, the UK (United Kingdom) recorded 40 and 39 fatal injuries to workers in 2019/2020 and 2020/2021 respectively, and this is consistent with the annual average over the last 5 years (HSE, 2020; HSE, 2021). This plateau in rates illustrates the need for new thinking and innovation.

Construction companies promote the zero-accidents mantra, but this cannot be solely achieved with over-reliance on manual and random on-site inspections. The adoption of drone technology could serve as an intervention strategy with the capability of providing real-time information and feedback for construction managers, safety managers and workers. This becomes even more important when work on site is currently being conducted using a phased approach due to the global Covid-19 pandemic. The Health and Safety at Work Act 1974 stipulates that all workers have a right to work in places where risks to their health and safety are properly controlled and safety managers have a responsibility to ensure that this goal is achieved. The idea of inspection or monitoring has been described by Toole (2002) as the frequent walk-around the site to acquire real-time information through direct observation and interface with workers. Depending on the complexity of the site and the project, site inspection could become a time-consuming exercise for the safety manager. It can also become irregular with failure to establish standard controls, get real-time data, and provide requisite feedback because Occupational Safety and Health (OSH) personnel are required to carry out audits and inspections (Cameron et al., 2007). Therefore, the strategy to design a drone game for virtual construction site inspection is to introduce technology that could ease inspection of real construction site safety issues, provide real-time feedback, and improve safety management (Hallowell et al., 2010). The use of drone technology is considered a useful tool due to its capability to fly over difficult to reach and highly dangerous locations by ensuring that workers are safe; there is improved and streamlined time to conduct site inspections; and improved audit trail, (Irizarry et al., 2012).

Furthermore, the construction market is seeing extensive use of drones on projects. The drone game should provide some level of awareness for safety managers and construction workers with the capability of learning how to fly a drone on a simulated construction site before undertaking the training towards acquiring the remote pilot drone licence with the UK Civil Aviation Authority (CAA). Therefore, playing the drone game allows the players to experience the speed at which inspections can be undertaken and the accuracy and level of detail that can be acquired; the ability of the drones to reach inaccessible areas of the construction site, and the capability to transfer real-time information. The cornerstone of implementing a good site inspection and safety initiative is fundamentally reliant on how the construction and safety manager can plan, manage, monitor, and control their work area in line with the CDM 2015 regulation which is why the adoption of the drone technology becomes important. The aim of this study is to explore the design and development of a drone game for a virtual construction site as a tool for engaging and educating construction managers and safety practitioners to adopt drone technology for site monitoring and inspections.

\section{RESEARCH MATERIAL}

\section{Use of Drones}

Drones or unmanned aerial vehicles (UAVs) is a technology that can be deployed in the construction industry for site inspection purposes. The current issues around limiting the number of workers on a construction site due to the Covid-19 pandemic (social/physical distancing) have consequences on the ability of safety managers to successfully undertake their site inspection responsibilities, most especially on complex or mega project sites (Zhou et al., 2018a). Technically, site inspection or walk around in itself can be maximised with the adoption of emerging technology like drones that are capable of undertaking site operational inspections in the unstructured construction environment (Zhou et al., 2018b). Drones are normally operated under remote/autonomous controls without any onboard pilot. That means, the operation relies mostly on human involvement and the acquisition of drone flying skills, knowledge, and experience. The deployment of drones for safety inspection purposes (Tantum and Liu, 2017), with the capability of providing real-time video of the ongoing construction activities cannot be ignored. The adoption of this technology as an add-on suggests that safety managers could potentially be able to provide immediate feedback and communicate with the workers in real-time, whilst not relinquishing their key responsibilities (Zhou et al., 2018a).

Within the UK construction industry, the most common causes of fatal injuries and the kinds of accident in the top five based on RIDDOR 2019/2020 and 2020/2021 are-falls from height; trapped by something collapsing/overturning; struck by moving, including flying object; struck by moving vehicle; and contact with electricity (HSE, 2020; HSE, 2021). Some of these fatal injuries could potentially have been detected or prevented via an aerial drone inspection. The rate of fatal injuries in the UK construction sector has not changed significantly over the last 5 years based on HSE statistics for the construction industry (HSE, 2020). The misunderstanding of the inherent risks associated with working in the construction industry can be linked to inadequate supervision and failures by management to address the unacceptably high rate of accidents (Gheisari and Esmaeili, 2019; Lawani et al., 2019). This could be due to the fixation in correcting the immediate causes or symptoms without addressing the root causes that could have been captured during routine audits, supervision, monitoring, or inspection. Therefore, the design of automated methods useful in identifying and monitoring hazards on a construction site can go a long way towards mitigating these types of accidents that workers can be exposed to (Fullerton et al., 2009). The development of the drone game for a virtual construction site is to serve as an educational resource to raise the level of awareness, improve the adoption of the real drone technology and to significantly increase the skills and competence of potential drone pilots towards successfully flying a real drone 
or gaining the pilot licence. The essence of the drone game is for players to be able to deploy a real drone on construction projects for site monitoring (Wen and Kang, 2014), inspection of building façades (Roca et al., 2013), safety inspection (Irizarry et al., 2012), ability to survey sites and projects (Siebert and Teizer, 2014), and construction progress monitoring (Han et al., 2015) without the personnel physically interacting with any of the dangerous activities on site. Other essential elements of using drones are the low cost of acquiring a drone, the speed at which information can be gathered, the high level of safety associated with data gathering and the manoeuvrability of the drones (Siebert and Teizer 2014).

\section{Safety Management and Real-Time Information}

Drones have the capability to collect real-time data on the safety features or hazardous situations on a construction site. In one example, a major contractor in South Florida deployed drones towards improving safety performance and designers could virtually meet to review real-time situations and make changes before construction began (Goodman 2017). Therefore, the adoption of the drone technology as an intermediary tool for remote site inspections and real-time feedback is an added advantage with features such as the ability to capture images and site videos, useful knowledge for decision-making, and site safety planning.

\section{Construction Monitoring and Inspection}

Rather than having the construction or safety manager conducting site inspections on foot; a fully trained drone pilot has the capability to safely operate the drone by collecting real-time site information whilst reducing the risk to every worker on site (Irizarry et al., 2012). It is understandable that the manual process of accessing, monitoring and inspection of motorways, bridges, wind turbines, building cladding systems, roofs, and façade systems can be timeconsuming and ineffective most especially when managing complex mega projects (Osunsanmi et al., 2020; Macrina et al., 2020). Therefore, deploying drones for monitoring and inspection purposes can improve site safety ( $\mathrm{Li}$ and Liu, 2019) while also effectively monitoring the distinct phases of construction project. The ability of the construction or safety managers to have a bird'seye view of the construction site can provide accurate and up-todate information of the site which helps in making more informed decisions about any ongoing work.

\section{Ethical Issues}

The use of drones has its own ethical dilemma. As the use increases on site, workers and the general public become more alarmed about their rights to privacy and data protection (Agapiou, 2021). Many workers perceive that deploying drones on a construction site is not all about improving efficiency, site safety and security but another way for the employer to utilise the drones to invade their private lives or work (Irizarry and Costa, 2016; Agapiou, 2021). The height at which drones are flown is another issue of utmost importance to worker and the public. The UK Civil Aviation Authority places the legal height limit of $120 \mathrm{~m}$
(400 ft) for flying a drone to reduce the risk of coming across other aircraft e.g., air ambulances and police helicopters that may fly below this limit. Also, the CAA advises that drone pilots must keep a minimum horizontal distance of $50 \mathrm{~m}$ between the drone and people, buildings and transport and to Keep at least $150 \mathrm{~m}$ away from residential, recreational, commercial and industrial areas. This raises safety concerns for tall structures, such as cranes and the safety of workers and the public during close inspections of structures or facilities of interest on site (Finn and Wright 2012). Therefore, this educational drone game is an opportunity for potential drone pilots to learn how to navigate and mitigate the consequences of any type of real drone failure without compromising the safety of anyone, misuse, and operator error that could result in physical injuries before they embark on flying an actual drone.

\section{GAME DESCRIPTION}

This section gives a vivid description of the final version of the game and the embedded functionality. The game was built using the Unity game engine for WebGL (Web Graphics Library) which renders interactive $3 \mathrm{D}$ graphics to be played in modern web browsers without the use of plug-ins. The game is designed to be a single player experience and requires the player to control a quadcopter drone using the keyboard and mouse to pilot it around a virtual construction site. By default, the player is taken through a tutorial at the beginning to get accustomed to the flight controls of the drone. This involves the player flying the drone through floating hoops that are at different elevations situated above the virtual construction site across different points. This activity is essential to familiarise the player with the flying controls on an active virtual construction site with machinery and workers to avoid, Figure 1.

Other features that are available to the player is their ability to change camera viewpoints between a third person camera by looking at the drone and an on-board camera that is situated on the drone, Figure 2. The third person camera is practical to navigate around the virtual construction site in wide open spaces in the same way an actual drone operator will use their eyes to observe the drone in the sky, while the on-board camera view is recommended to be used when the drone is near objects and people. Again, this mirrors how a drone operator would control the drone for real construction site inspection purposes.

The objective of the player is to fly the drone to inspect the virtual construction site and locate hazards. This is achieved by piloting the drone using the inbuilt compass at the top of the screen that indicates the general direction and range of the drone to hazards. When the drone is close to a hazard, the player must actively spot and capture the hazard using the on-board drone camera. The on-board camera contains a viewfinder that changes colour when a hazard is detected and by default, when there is no hazard in view, the viewfinder remains black. The viewfinder turns to red if the hazard is in view but not the centre of focus, and it turns green if the hazard is centrally focused. Once the hazard becomes centrally focused, the player can enter a more zoomed-in version of the hazard where the player can play a minigame for a 


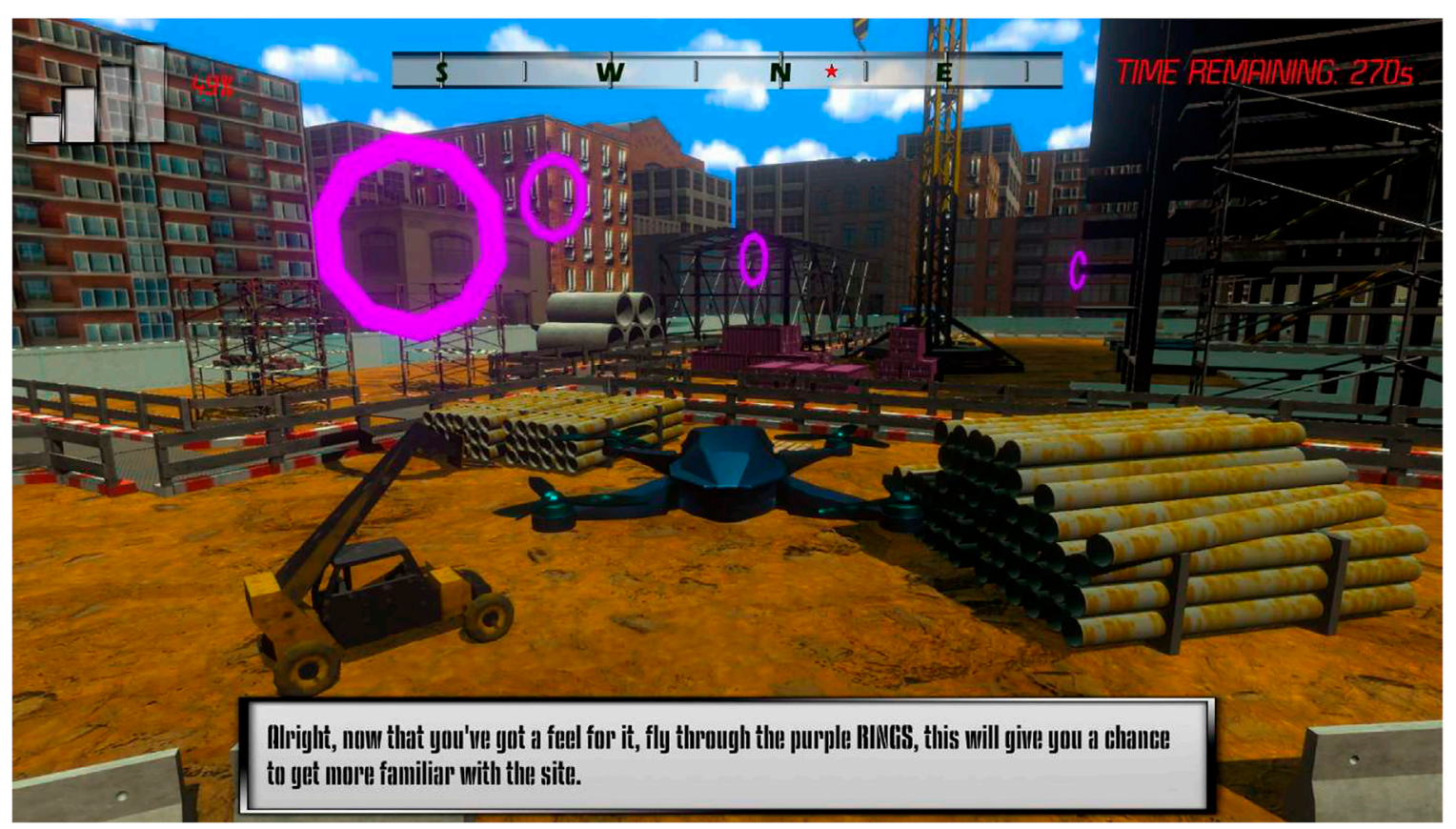

FIGURE 1 | Screenshot of tutorial hoops the player must pilot the drone through to learn the drone controls.

more detailed review of the hazards, which could be multiple hazards. Figure 3 shows the full sequence of using the viewfinder to locate a hazard and enter the minigame. The top left screenshot shows the black viewfinder indicating no hazard. The top right screenshot shows the red viewfinder indicating a hazard is in view but not fully focused. The bottom right screenshot shows the hazard is in full focus and can proceed to the minigame. The bottom left screenshot shows the hazard minigame with the viewfinder removed to provide a better perspective of the temporary support prop that has moved and become loose.

When a player is in the minigame state, they must actively locate the hazards and select the hazards by hovering the mouse over the hazard. If the object is a hazard, it will turn red, and the player can click to confirm identifying the hazard with an audio cue that will signify if they have located the hazard. If the object in question is not a hazard, then nothing happens, and the player resumes inspecting and locating hazards in the virtual site. A total of 13 hazards were incorporated around the virtual construction site. The full list and description of hazards can be seen in Table 1.

The players have limited amount of time to spot all the hazards in the virtual construction site. This simulates the battery life of the drone and the reality for the operator of the drone to work quickly and efficiently. This provides a bit of pressure and motivation for the player to perform the task, otherwise the game would become too easy and not engaging. If the player identifies all the hazards and complete the game, the results screen will be presented showing the hazards that they located along with how dangerous the potential risk was. If the player fails to find all the hazards in the allotted time, then only the hazards they found will be shown to the player and the missed hazards will be shown with a blurred-out image as a hint but not informing the player of the exact hazard or its location. The player is then encouraged to replay the game to find all the hazards so that they can see the ones they missed out.

\section{RESEARCH METHODOLOGY}

The game was developed using an iterative agile approach to development called Scrum (Scrum.org, 2021) which is a common and efficient approach to developing a game (Keith, 2010). In Scrum, the project is broken down into sprint's that typically last between one to 4 weeks. A sprint is a focused body of work usually on a specific goal, which incorporates a planning stage at the beginning and a retrospective stage at the end. The retrospective stage is important as this allows the project team to analyse working processes during the sprint and therefore future consideration can be given to how to improve the efficiency of development as the project continues (Przybylek and Kotecka, 2017). For this project, the sprints were weekly and the whole project was set over a period of 24 weeks as this was the timeframe available for the project. This gave 24 iterations of the project during the entire process of development. As well as using Scrum, the project was split into two phases. The first phase preproduction was where the game concept and design were constantly prototyped to figure out what the game design should be and how to gamify the educational experiences to meet the aims of the project. The second phase, i.e., the production made use of the existing solid foundation in refining the game content to become professional looking whilst making small iterative changes to improve the overall game design based on more extensive playtesting feedback. This 


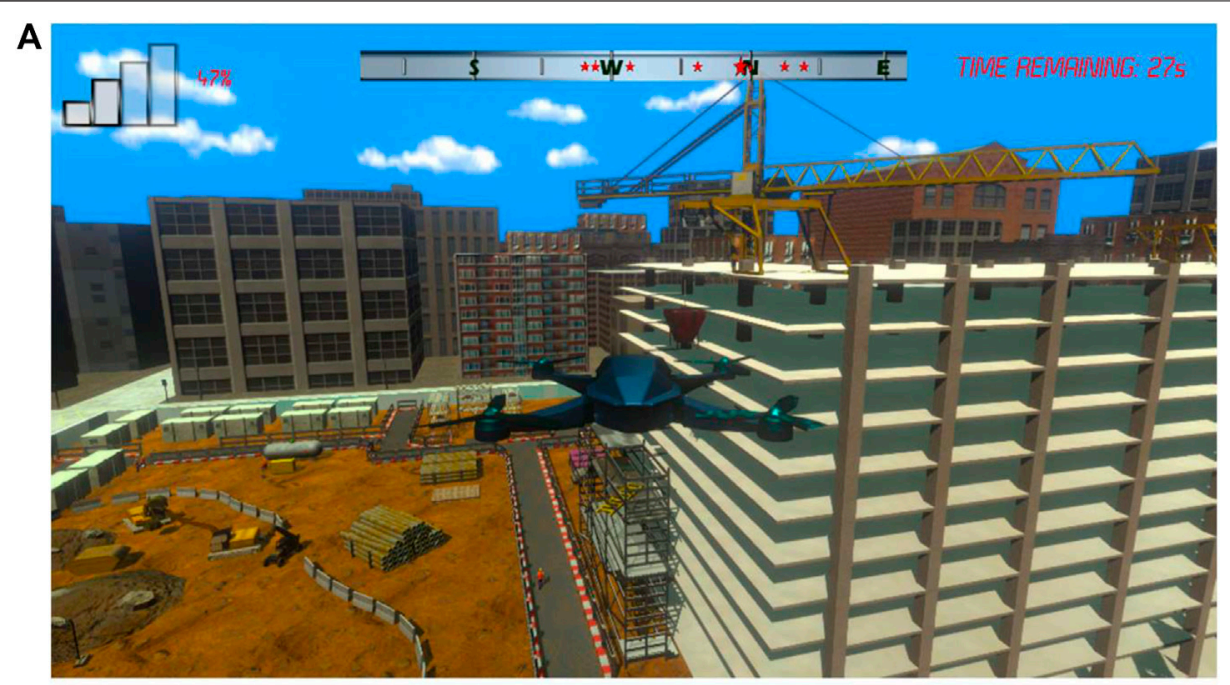

B

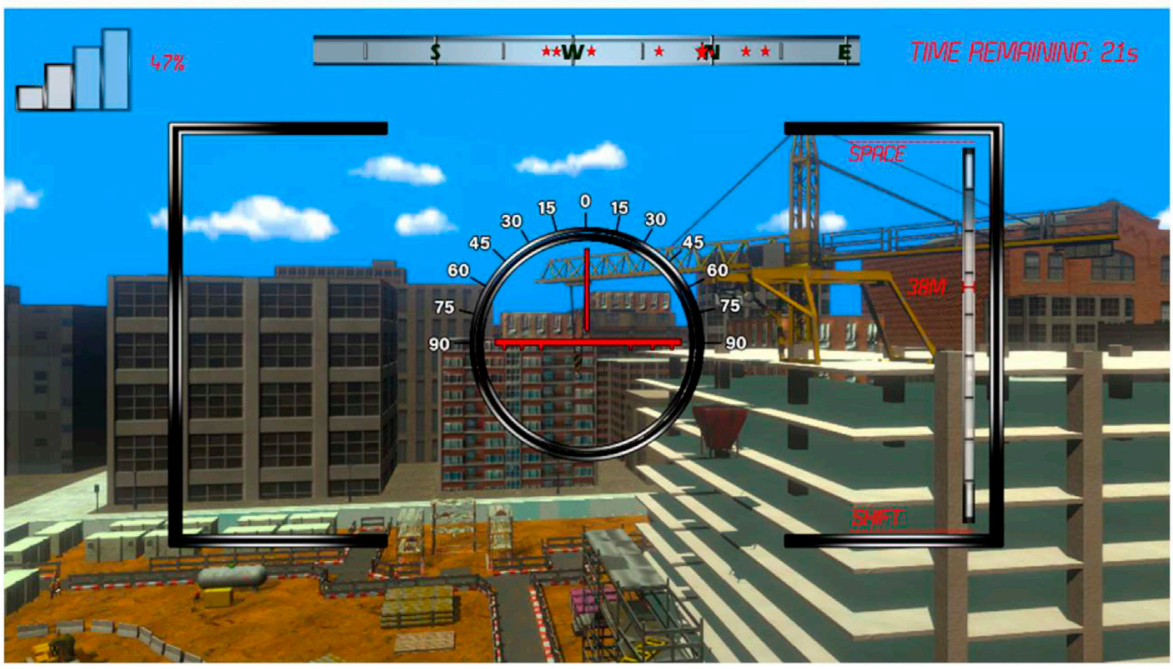

FIGURE 2 | (A) image shows the third person viewpoint and (B) image show the on-board camera viewpoint when piloting the drone.

then allowed the game to be evaluated with the participants of the study. Figures 4, 5 shows the focus in each sprint till the end of the project for both preproduction and production and therefore how the project was organised using an iterative approach.

It is worth noting that the final organisation of the project was not planned upfront as this would go against Scrum and agile methodology. However, key milestones for the project were planned upfront which coincided with key sprints which are highlighted in orange (sprints 4, 8, 12,16, 20, and 24). Since the project adopted Scrum and agile methodology, the final focus of each sprint became dependent on the state of the project at that time. It was useful to have points in the project where the stakeholders could give formal feedback on the progress of the project to ensure positive direction for the project and the game, and if not, then the direction of the project could be changed. For instance, during Sprint 4: Concept pitches, the development team presented three viable game ideas but the key stakeholders were very enthusiastic about two of the ideas. After the concept pitches, it was decided to take this feedback on-board and consolidate both ideas together. This approach significantly helped to shape the outcome of the game, and this would not have been achieved if stakeholders were not part of this process in the early stage. A second stage of stakeholders' involvement during Sprint 20: Playtesting with stakeholders was another step that helped shaped the project positively. The stakeholders in this case were the project team made up of six gamers and lecturing staff within the Applied Computer Games and Construction and Surveying departments. The playtest confirmed the game was engaging and fun, but it had issues with the readability and understanding of the user interface and the tutorial. This discovery was further factored into future sprint planning to address the concerns. This reactive and agile approach to the 


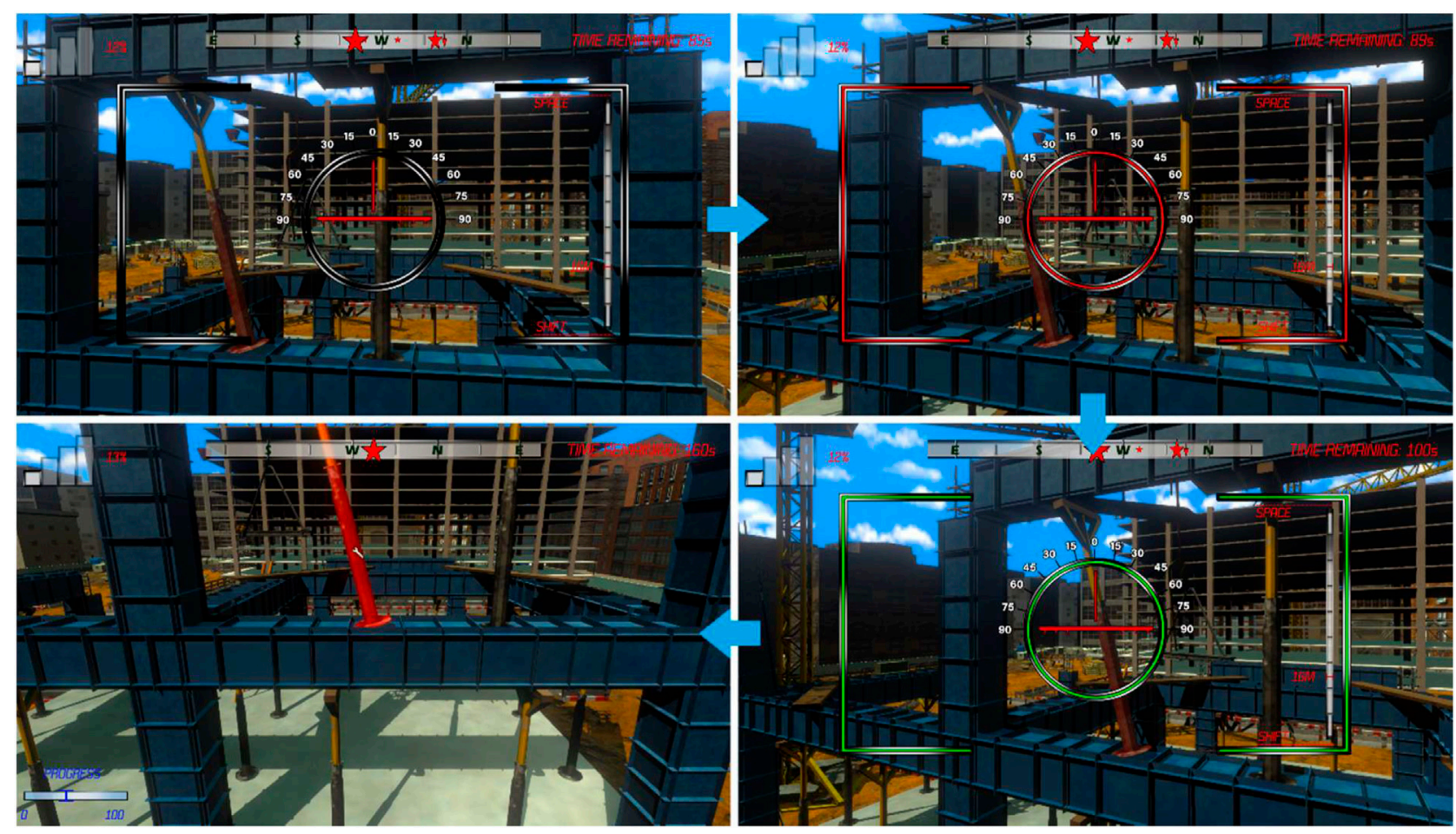

FIGURE 3 | Screenshots showing the different states the viewfinder can be in when trying to locate hazards using the on-board camera of the drone.

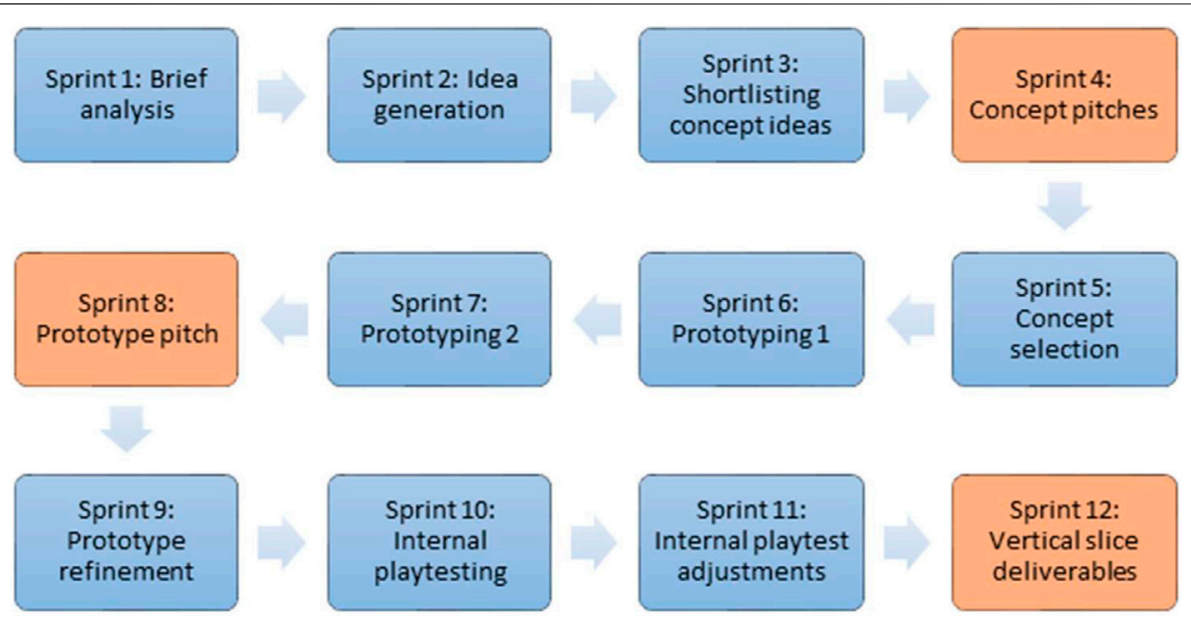

FIGURE 4 | Diagram showing the preproduction phase of game development for this project.

game development ensured that time and resources were spent where they were most needed, and the focus of the game was at the forefront of the design of the project throughout.

\section{GAME DESIGN AND METHODS}

The following game design and methods used were applied across the lifetime of this project, though during specific sprints they sometimes became the focus depending on the stage of the project. Before going into the detailed game design methods adopted, it is important to clarify the rationale for creating this novel game. By creating a game that introduces the concept of drone technology in an engaging and inexpensive way for those that manage, monitor and inspect construction sites, the expectation is that by playing this game, it will motivate them to adopt the physical technology (the actual drones) quicker and more efficiently 


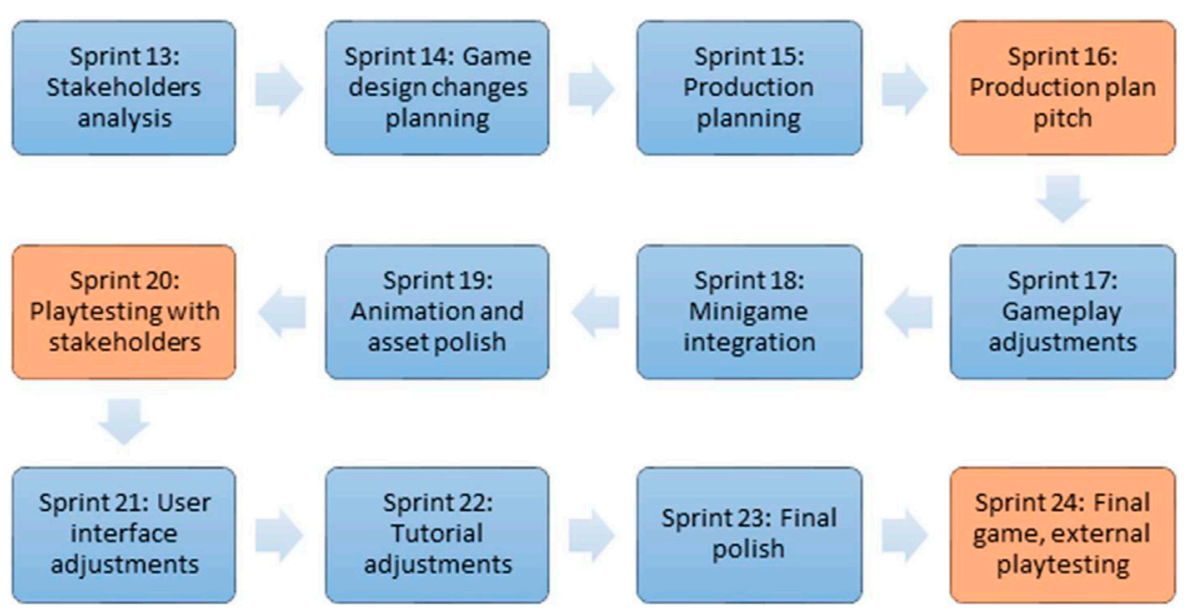

FIGURE 5 | Diagram showing the production phase of game development for this project.

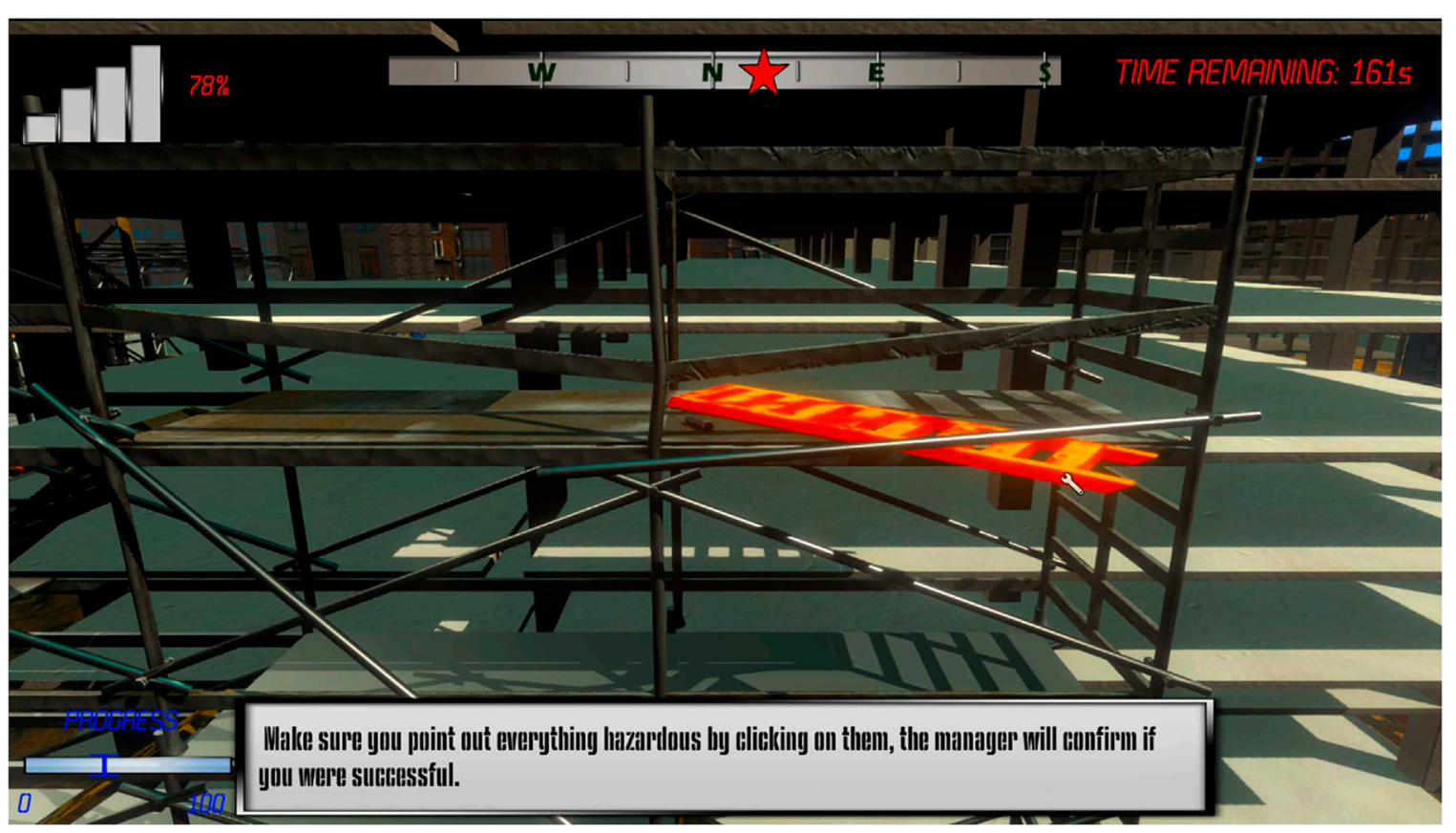

FIGURE 6 | Example of the hazard minigame. If a player spots a hazard using the drone they will be taken to a zoomed-in version of the hazard where they must click on all the hazards which will highlight red when clicked to signify and confirm it was a hazard.

by experiencing the benefits of drone usage in the virtual construction site.

\section{Ethical Approval}

This study sought ethical approval from the School of Computing, Engineering and Built Environment Ethics Committee for the non-invasive research involving human participants which was approved. Participation was voluntary with the option to withdraw at any time, and the purpose of the study was disclosed through adjoining instructions. Ethical issues such as personal disclosure, authenticity, credibility, and personal privacy were also addressed in line with the UK General Data Protection Regulation (GDPR). The process of participant selection adopted the nonprobability purposive sampling strategy as it was considered useful for situations where targeted participants could be sampled quickly and where sampling for proportionality is not the primary concern. The rationale for the purposive sampling approach was to get the 
TABLE 1 | Description of all hazards in the game.

\begin{tabular}{|c|c|c|c|}
\hline Hazard type & Hazard area & Danger level & Description \\
\hline Fallen ladder & Scaffolding & Medium & A ladder has fallen connecting to levels of the scaffolding and is partially hanging off the scaffolding platform \\
\hline Loose support beam 1 & Scaffolding & Medium & A supporting beam on the scaffolding is loose \\
\hline Loose support beam 2 & Scaffolding & Medium & A supporting beam on the scaffolding is loose \\
\hline Disconnected cable & Crane & High & Cable of lifting hook on crane has become disconnected \\
\hline Unstable acrow prop & Side building & Medium & Acrow prop to hold up supporting structure of side building is misaligned \\
\hline Sheared cable & Pile driver & Medium & Cable for the pile drive has sheared \\
\hline Pipe 1 & Pipes storage & Low & Unrestrained pipe in storage area \\
\hline Pipe 2 & Pipes storage & Low & Unrestrained pipe in storage area \\
\hline Pipe 3 & Pipes storage & Low & Unrestrained pipe in storage area \\
\hline Pipe 4 & Pipes storage & Low & Unrestrained pipe in storage area \\
\hline Hoist bucket & Top of main building & High & One cable on the on the hoist bucket has snapped leaving it dangling \\
\hline Employee smoking 1 & Propane tank & High & Employee is hiding and smoking next to a propane tank \\
\hline Employee smoking 2 & Propane tank & High & Employee is hiding and smoking next to a propane tank \\
\hline
\end{tabular}

TABLE 2 | Frequency of study participants.

\begin{tabular}{|c|c|c|c|c|c|}
\hline Male/Female & & Frequency & Percent & Valid percent & Cumulative percent \\
\hline \multirow[t]{3}{*}{ Valid } & Male & 29 & 61.7 & 61.7 & 61.7 \\
\hline & Female & 18 & 38.3 & 38.3 & 100.0 \\
\hline & Total & 47 & 100.0 & 100.0 & - \\
\hline
\end{tabular}

opinions of the participant population which resulted in 47 participants (29 males and 18 females). The participants for the testing session were not required to disclose personal information aside their gender neither was it mandatory to have the requisite knowledge of construction projects. However, the baseline for participation was for the players to have the fundamental understanding and some experiences of playing games and therefore could validate if the game was enjoyable and realistic as part of the core objective of the playtest i.e., testing both the objective (usability, reliability, and functionality) and subjective (convenience, enjoyable, engaging) characteristics of the drone game.

\section{User Experience}

The user experience focused on how the player's experience can be improved and how players interact with the game, such as navigation, ergonomics, and usability when playing the game (Irizarry et al., 2012). The user participation evaluation was performed following a simulated task with 47 participants. The players were required to fly the drone over the virtual construction site as a form of inspection and spot specific number of hazards within the construction site without crashing into any structure or workers.

\section{Usability Testing}

Systems have traditionally been designed and developed through a technology-centred perspective (Endsley et al., 2003). In such a perspective, the designers would accept the technology as it is and replicate same technology in different domains without considering the principal element-the end-user (human). In a technologycentred perspective, the end user and all its requirements are considered as identical even in different domains. For this study, a user-centred approach was employed. Unlike the technologycentred approach, the very first issue that this study resolved in a user-centred perspective was to ensure that the technology is usable-considering the real users' experience and their own requirements in a specific domain (Irizarry et al., 2012; Gheisari and Esmaeili, 2019). That means easy set of controls that are intuitive i.e., easy to figure out how to play the game and improve, cognitive affordance, visual language, and accessibility towards reaching a wider audience. This user-centred usability-based step provided a grounded base for understanding the requirements for practical application of the drone technology in a domain. Developing the drone game technology seemed particularly useful for safety inspection practices. The main issue that needed to be resolved was whether this technology could be used by construction and safety managers and construction workers. A usable system should be easy to use and learn to work with the least number of design errors by always keeping the game state clear and comprehensible.

\section{User-Focused Perspective/User Experience}

A user-centred approach was employed in the development of this game following standard practices employed within the games industry (Irizarry et al., 2012; Gheisari and Esmaeili, 2019), by providing satisfying feedback in every action through art, animations, sound effects, camera behaviour, and user interface. The design also ensured that added elements like the visual effects, art, level of design and audio increases the level of satisfaction provided by the game mechanics. Since this project is focused on educating construction workers who may not be adept with playing computer games, the game had to be designed with the specific 
user in mind, using the on-boarding tutorial as a way of introducing players into the game and the mechanics and goal of the game. Therefore, the game had to be simple to operate, easy to access and intuitive to use. Early design decisions were made for the game to run in a browser using WebGL to facilitate easy access for players. Furthermore, the decision to use WebGL was founded on the premise that most people would have played some form of browser-based games and therefore, more likely to understand how to operate a game in their browser or at the very least, be comfortable with using a browser. That meant by using WebGL, the game was accessible and readily available to anyone.

To ensure the drone game was easy to play, accessibility was a fundamental priority throughout the development, and this was not just limited to the technology of choice for this project. User stories were created based on the target audience to gather the requirements for this project. This led to several prototypes of small portions of the game which were tested internally to ensure that the ideas in the user stories were appropriate, meaningful, fulfils the goal of the game and fit with the game design intentions. Several ideas were discarded during design but those that seemed plausible were collated and expanded before being documented in the form of a game design document. This outlined the key features the game must have to be successful from the perspective of users and what the current designs were that would achieve these goals. The primary features identified were:

- The piloting of the drone had to be simple, feel intuitive and enjoyable to fly.

- The interface that users would play through should be simple and easy to understand even with no prior knowledge of playing games.

- The construction site itself had to feel animated, busy, and realistic enough to feel believable.

- The hazards had to be as realistic as in a real construction site but also visible enough to be able to identify them, otherwise users will not learn anything or enjoy the experience.

- For users to retain the knowledge and make the experience more impactful, simple mini games with emphasis on construction hazards was introduced (Figure 6). This is important in highlighting the significance of finding the hazards which in turn would show why using a drone is safe and beneficial to undertake this type of site inspections.

The steps above outline the preproduction process of the game with emphasis on gathering analysis requirements for the drone game (Figure 4). It involved deducing the key features and requirements by the stakeholders and it was also essential that a vertical slice-a functioning playable prototype of the game was produced to ensure the idea itself was viable. After showcasing the vertical slice to multiple stakeholders, it was evident that the overall idea of the drone game as an educational resource was practicable and could proceed into full production with the general design needing some iteration.

\section{FINDINGS AND DISCUSSIONS}

\section{Cognitive Design}

The full production of the game was crucial to ensure that the cognitive design of the game including the functional and emotional expectations aligned with that of the target audience. The principle of the game was not only to teach users about the benefits of drone usage on a construction site for inspections and the practicality of spotting hazards, but to be an enjoyable experience and an educational resource capable of motivating users to interact and engage more with the drone simulation. Users that enjoy interacting with a game or find it fun are more likely to retain information (Przybylski et al., 2010). The focus of the game was not only to learn the basic skills of piloting a drone or how to safely operate and fly a drone, but to use a drone to spot or identify hazards so that users can visualise the benefits that drones offer for construction site inspections, whilst avoiding the inherent risks of collision, damage and injury associated with learning to use such equipment on actual sites. To credibly do this, the game had to feel natural, easy to learn and fly the drone without complex interfaces, engaging the player and feel realistic which was a difficult challenge. Striking a balance between these features which can often compete with one another is a difficult choice when designing an educational game. To resolve these challenges, the development of the game meant addressing the following key points during the game design:

- The design of the construction site, scenario and hazards presented feel realistic.

- This design should be easy to use or recognise for someone that does not play games.

- The drone game should be engaging and fun to play to promote players to experience the whole game and to help them retain knowledge.

By reviewing the various aspects of the game design using these criteria it resulted in several design and development issues being averted. For example, the flying of the drone itself was designed to feel realistic and with the use of simplified controls to avoid overloading the cognitive abilities of the user (Ackerman, 1988; Lawani et al., 2018). The drone also had to be practicable in terms of the size and its starting position in the virtual construction site to allow users to be fully immersed in the simulation. Most importantly, the drone game was designed to have elements of fun and an enjoyable experience to pilot and designed to be practical and realistic. Without the integration of the engaging and fun elements, users will be reluctant and amotivated to play the game and therefore struggle to comprehend the significance of using a drone for construction site inspection. Therefore, designing the drone game by integrating the fun features with simplified controls to lower the cognitive load was a challenge but it improved gameplay. Furthermore, the use of controls that are too simplistic as part of the design process could diminish the believability of the simulation. However, designing the game such that the controls are real and complex could potentially mean players 
TABLE 3 | Likert Scale playtest questionnaire.

\section{Question}

$\begin{array}{lll}\text { Response set } & \text { Likert scale 1 } & \text { Likert scale 6 } \\ \text { Fun } & \text { Not fun } & \text { Very fun } \\ \text { Understanding } & \text { No understanding } & \text { Full understanding } \\ \text { Intuition } & \text { Not intuitive } & \text { Very intuitive } \\ \text { Ease } & \text { Not easy } & \text { Very easy } \\ \text { Compass } & \text { Not useful } & \text { Very useful } \\ \text { Clarity } & \text { Not clear } & \text { Very clear } \\ \text { Fluidity } & \text { Not fluid } & \text { Very fluid } \\ \text { Realism } & \text { Not realistic } & \text { Very realistic } \\ \text { Usefulness } & \text { Not useful } & \text { Very useful }\end{array}$

How fun did you find the game?

Do you understand the benefits of using drones on a construction site?

How intuitive did you find the flight controls?

How easy or difficult did you find the hazard mini-games?

How useful did you find the compass for locating hazards?

How clear was your objective in the game?

How fluid did you find the transition between controlling the drone and entering mini-games and vice/versa?

How realistic did the construction site feel?

How useful did you find the different UI elements?

Usefulness

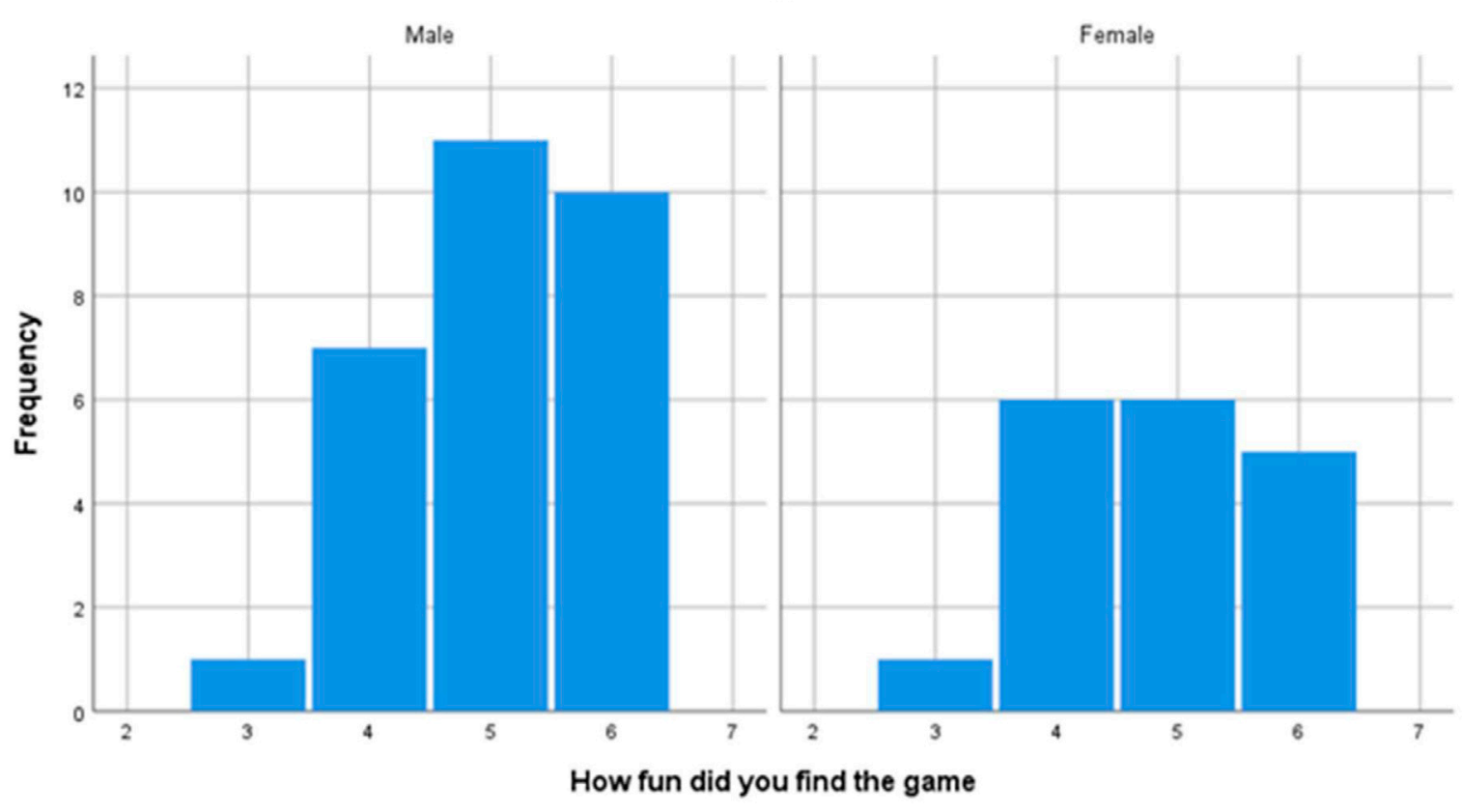

FIGURE 7 | Questionnaire participants results for how fun they found playing the game.

taking longer time to understand how to operate the drone and hence, the user experience will be less engaging and less fun while learning how to fly a simulated drone for construction site inspections. Therefore, the design and development of the drone game had to strike a balance between believability and realism, enjoyment, and ease of use.

\section{Usability Testing/Playtesting}

Usability testing is essential to ensure a product is useable. However, the design of the drone game went a step further with playtesting to be able to evaluate the user experience not just from a user interaction-based approach but also their cognition, emotion, and enjoyment (Pagulayan et al., 2018). This approach could be very subjective as people's cognition, emotions and what they enjoy can differ greatly. Therefore, this study considered playtesting as an extremely important lifecycle of developing the drone game. This was achieved by playtesting multiple times both internally (within the development team) and externally (preliminary testing with the participants). This helped validate if the objectives of the drone game were met by ensuring it was functional, usable, reliable, fun, enjoyable, and meeting the educational goals. The development of the drone game also went through continuous informal testing by the development team to allow the design team to gather informal feedback quickly and therefore design improvements to the game. The informal testing sessions helped to ensure that the overall design of the game and the way it interacts felt credible, indicating that the game was practicable with a high degree of confidence. To formally validate that the drone game was fun, understood, intuitive, easy, clear, fluid, realistic, and useful whilst teaching the player about the use of drones for construction site inspections and hazard identification, a preliminary external pilot playtest was 


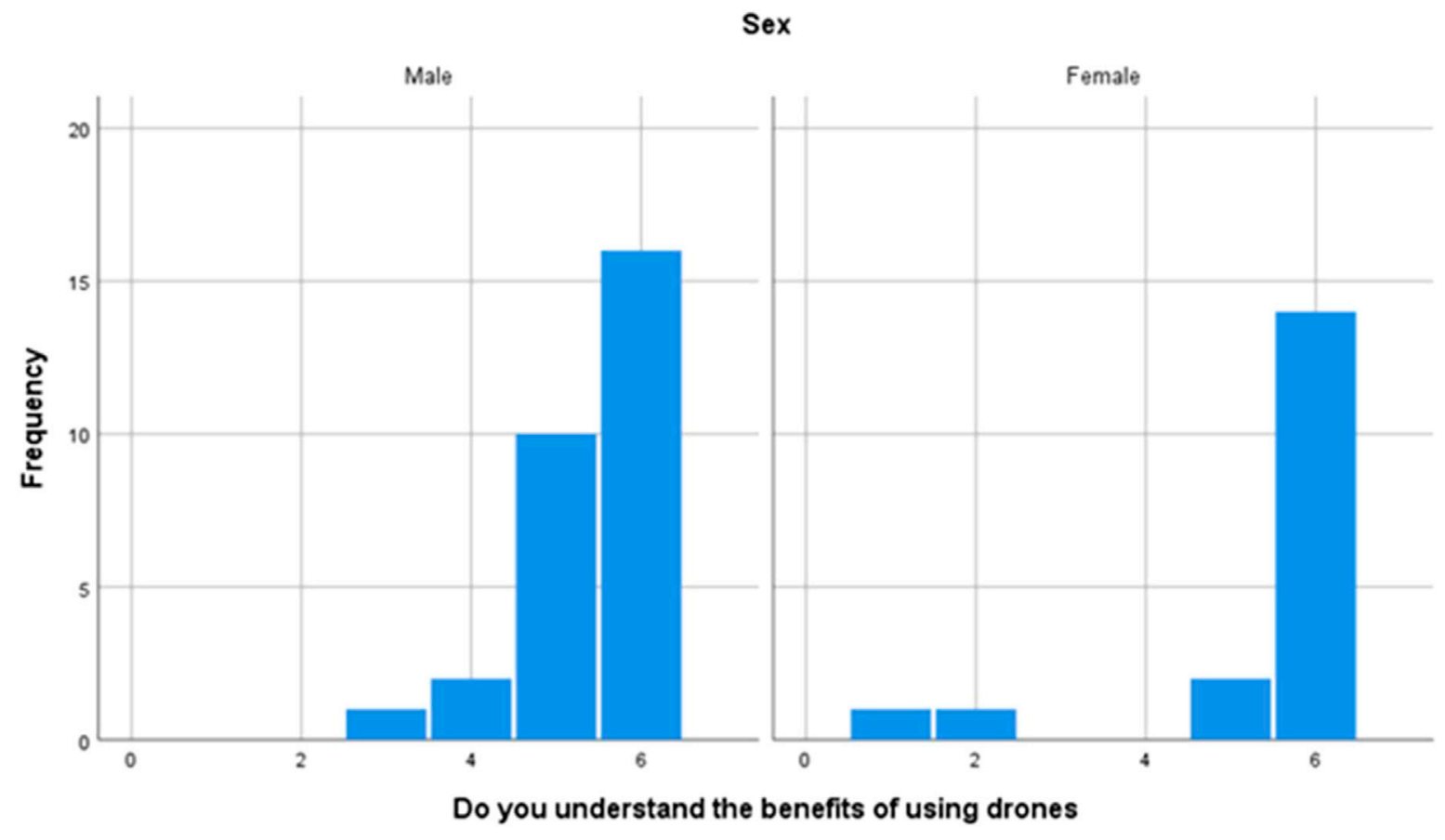

FIGURE 8 | Questionnaire participants results for the understanding of the benefits of using drones on a construction site.

conducted with 47 participants (Table 2). From the output shown, there were 29 males (61.2 per cent) and 18 females (38.3 per cent) in the sample population.

The data collection adopted the Likert-Scale approach to scaling responses in survey research to measure participants' responses to a particular question adopting the ordinal measurement so that the attributes can be rank-ordered, using the self-designed Google Forms questionnaire, see Table 3. The study used the Likert Scaling unidimensional method which is the branch of measurement that involves the construction of an instrument that associates qualitative constructs with quantitative metric units as they are easier to understand.

The inspection of the shape of the histogram provides information about the distribution of scores based on the assessment conducted. The findings implemented a benchmark where participants' responses were grouped into two major categories based on gender-male and female. The participants' responses were also grouped into two-levels 1, 2, 3 was considered as negative whilst 4, 5, 6 were classed as positive. The results from 45 participants (about 96\%) that participated in the playtest of the drone game for construction site inspection indicated it was fun to play and enjoyable with only two of the game players indicating otherwise (one male and one female player), Figure 7.

It is suggested that the type of multi-rotor drone implemented in this game (quadcopters-four rotors) are also useful for professional aerial mapping and aerial surveying (Tkáč and Mésároš, 2019; Shahmoradi et al., 2020) which makes the flying and inspection skills acquired from gameplay directly applicable and transferrable to live construction site inspection and monitoring. Most of the participants population made up of 28 males and 16 females (44 or 94\%) understood the benefits and the significance of using drones for construction site inspection (Figure 8).

The significance of this study is timely in introducing and exposing the participants to the educational game most especially during the Covid-19 pandemic where workers needed to be physically distanced; work packages had to be sequenced; and with restrictions on the number of workers that can be present on site at any point in time during the pandemic. Therefore, the ability to deploy a drone for site inspection purposes that allows the project team to have an overview of work progress would be an added advantage to monitoring the schedule of work and an improvement on site safety and security (Han et al., 2015; Goodman, 2017). The benefit of flying the drone over a virtual construction site could enhance the skill and experience of flying a real drone useful for identifying the root causes of accidents on site and for prioritising the potential preventive measures. Other potential benefits could be in monitoring operations of boom vehicles or the use of lifting equipment like cranes working near overhead power lines or unprotected edges (Gheisari and Esmaeili, 2019), for seamless information collection for construction and safety managers (Li and Liu, 2019), and improved site safety (Tkáč and Mésároš, 2019).

Most participants indicated that the game was intuitive and easy to pilot the drone (Figure 9), and they found the hazards in the simulated construction environment real, which satisfies one of the main requirements of the playtest. However, it has been suggested that the additional skill required for controlling or piloting a drone when added to the safety manager's 

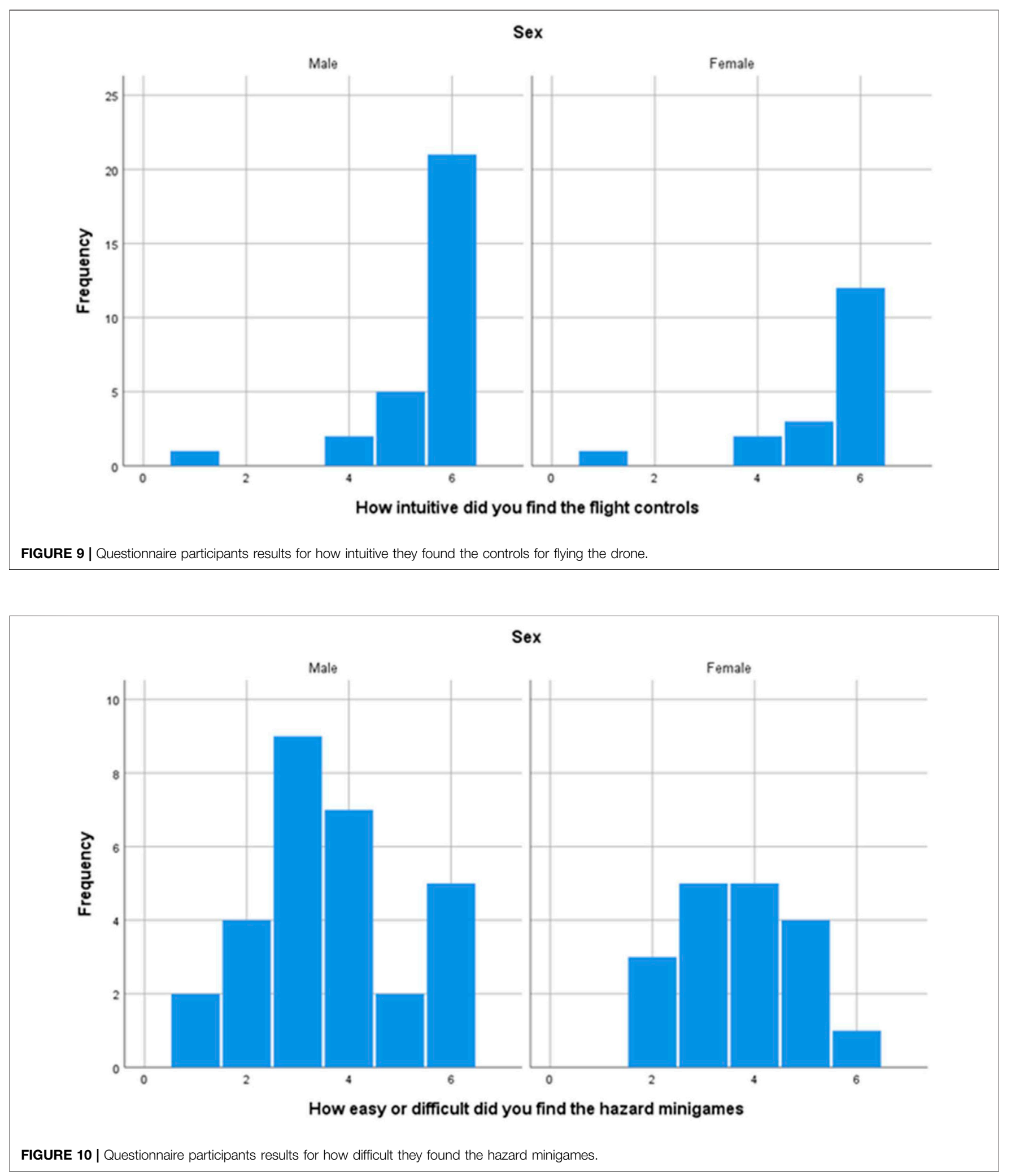

responsibilities could become a more onerous task (Irizarry et al., 2012). This study indicates that playing this game and understanding how drones can be implemented on a project site for inspection purposes might be an added benefit to the project team and a source for building on their practical and individual experiences (Tkáč and Mésároš, 2019). 


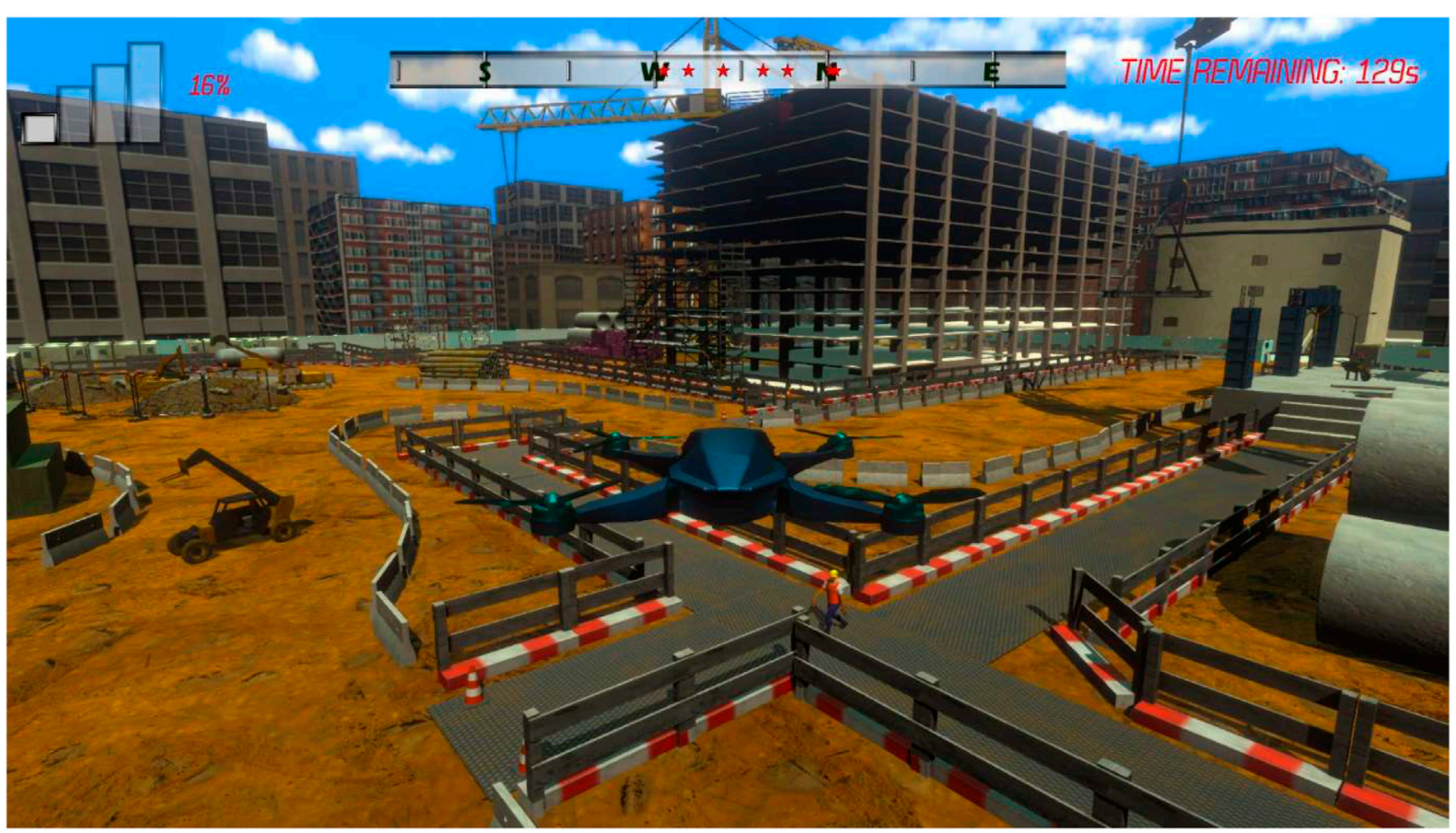

FIGURE 11 | Screenshot of game showing pedestrian access routes on the construction site.

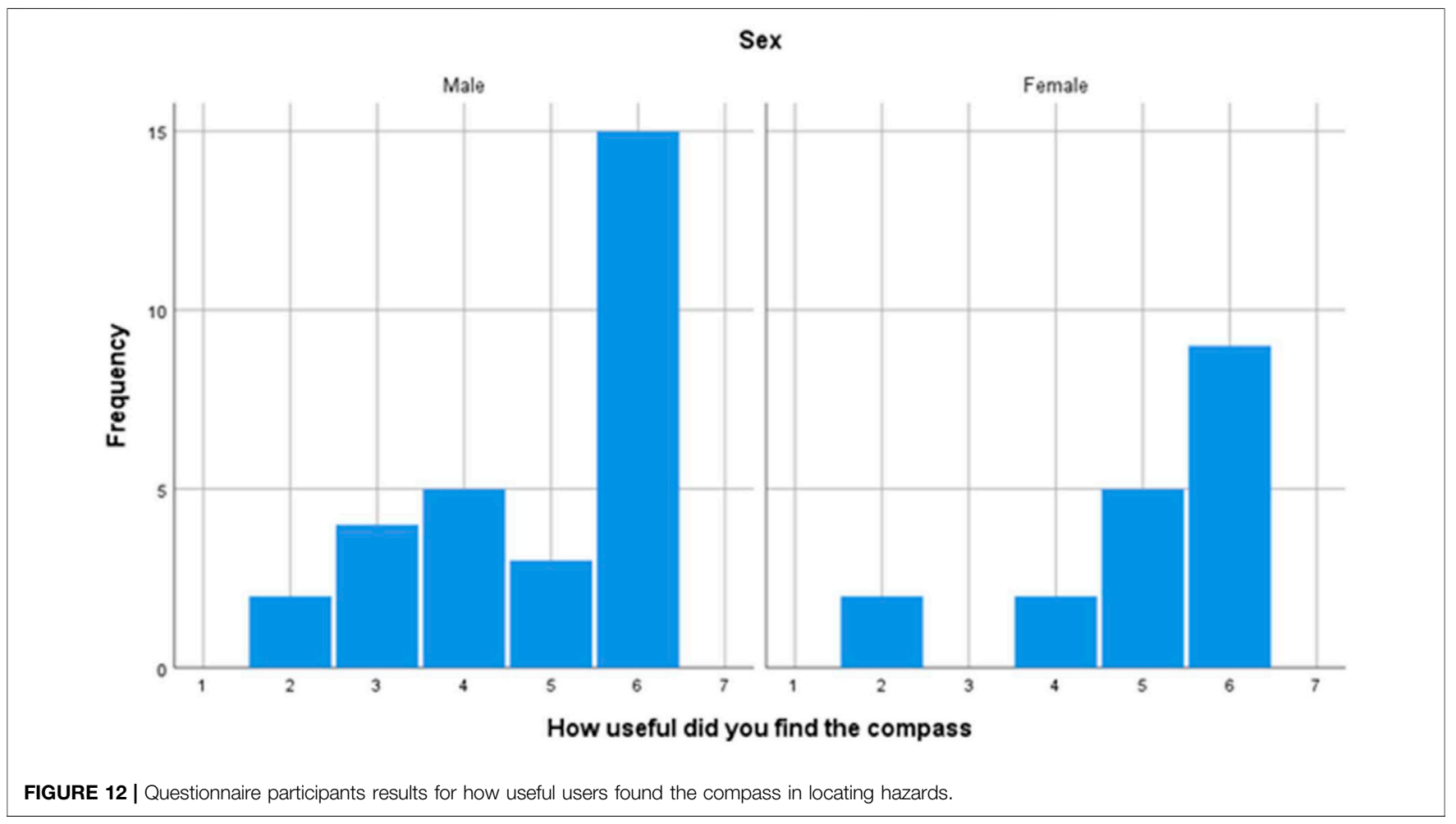

Although the hazard minigame which is useful for hazard identification was considered fun by some players (Figure 3), almost half of the players (23 players, Figure 10) struggled to complete the minigame task or understand that the requirements of the hazard minigame was for obstacle avoidance, (Shahmoradi et al., 2020). The hazard minigames were important for the 


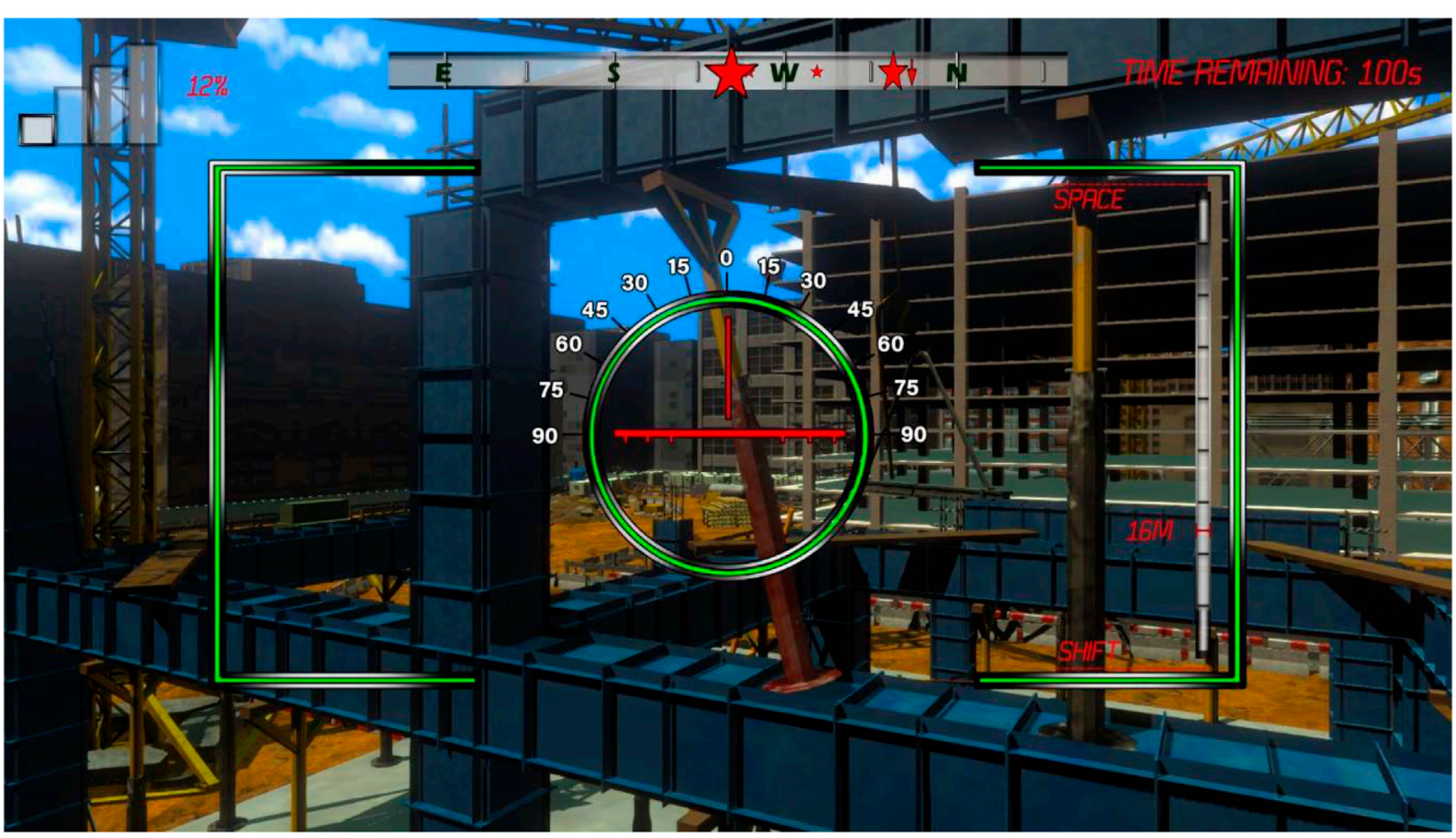

FIGURE 13 | Screenshot of game showing using the compass at the top of screen with the star symbol on it to locate a hazard which has changed the drone view finder to green.

players to understand and to gain the experience required for identifying construction site hazards as it is a useful skill required for inspecting and monitoring construction sites (Macrina et al., 2020). Although the feedback from participants suggested that the game was a success, further refinements and other minor improvements were incorporated into the final version of the game e.g., clearly designated pedestrian access routes and vehicular routes (Figure 11).

Thirty-nine participants (23 males and 16 female players) indicated that the compass was useful for hazard location and progress monitoring of ongoing activities within the virtual construction site. However, eight participants suggested that there were key issues that needed to be resolved in the gameplay that will be useful when flying a real drone on a construction site. For example, elements of the user interface like the signal metre that displays the range the drone could fly before losing signal could be designed to be more explicit (Figure 12 and Figure 13). Therefore, adopting the CAA guidance regarding keeping a minimum horizontal distance of $50 \mathrm{~m}$ between the drone and people, buildings, and transport and to Keep at least $150 \mathrm{~m}$ away from residential, recreational, commercial, and industrial areas might have an impact with the compass in terms of signal loss. However, most participants acknowledged that the in-built compass for identifying and zooming into a hazard was useful in easily capturing site hazards within the virtual construction site. A fully functional compass that is integrated into the drone game could be useful for data collection from embedded video cameras or vision cameras and this will make the adoption of similar drones more useful in identifying hazards during construction, monitoring resources and worker safety on a real construction site (Gheisari and Esmaeili, 2019).

The drone game was designed so that players would be able to fly the drone on a virtual construction site for optimising, inspecting, and monitoring the construction work process and progress. This included the ability to fly the drone for undertaking safety risks assessment within the virtual construction site like what is required on a live site; routine inspections including site surveys, asset protection, and inspecting areas and structures that are inaccessible to operatives; and general conditions of the construction site. About 45 (96\%) participants considered that these objectives were clearly presented within gameplay and fulfilled a function of the game design. In a practical sense, these objectives could potentially minimise the operational cost of training for inspecting and monitoring actual construction sites (Figure 14).

The playtest sessions for stakeholders proved to be especially useful towards improving the drone game elements in terms of the transition between controlling the drone and entering minigames and redesigning of certain features of the game. For example, the signal meter graphics was redesigned analogous to a wireless signal meter and this aesthetic improved a revamped Heads-Up Display (HUD) from the perspective of the players. The external playtest has also been extremely useful as this has led to improvements in the keys used for the controls such as an alternative set that suited non-traditional game players. The hazard minigames were also improved by using better in-game communication and instructions to guide the players stepwise, thus making the 

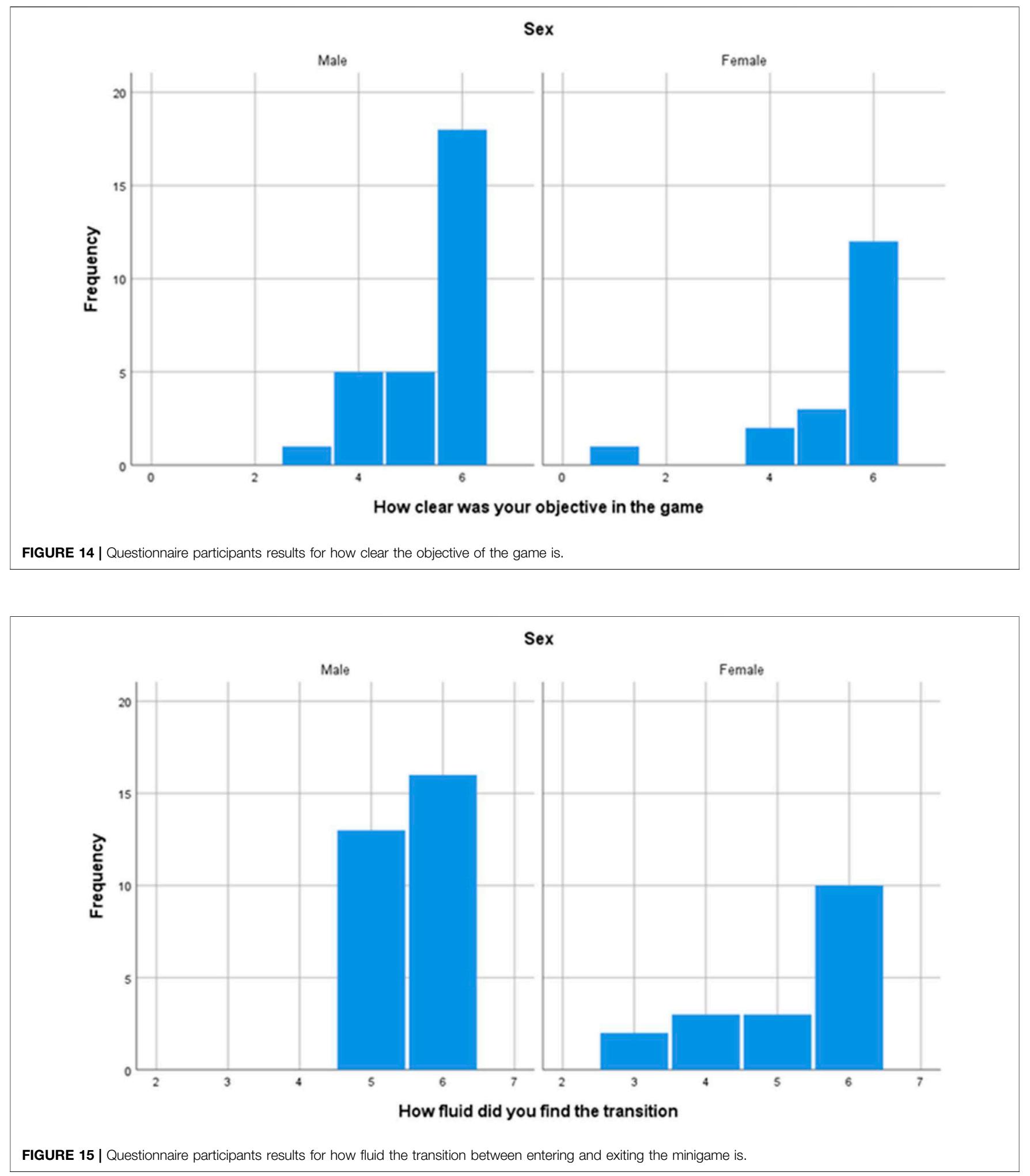

virtual construction site layout and the hazards more obvious. Significant playtesting of the drone game will be further conducted with the specific target audience (safety managers/inspectors, construction managers/supervisor) to ensure that the game is appropriate and without ambiguity. Forty-five participants (29 males and 16 females) indicated the game transition was easy in 


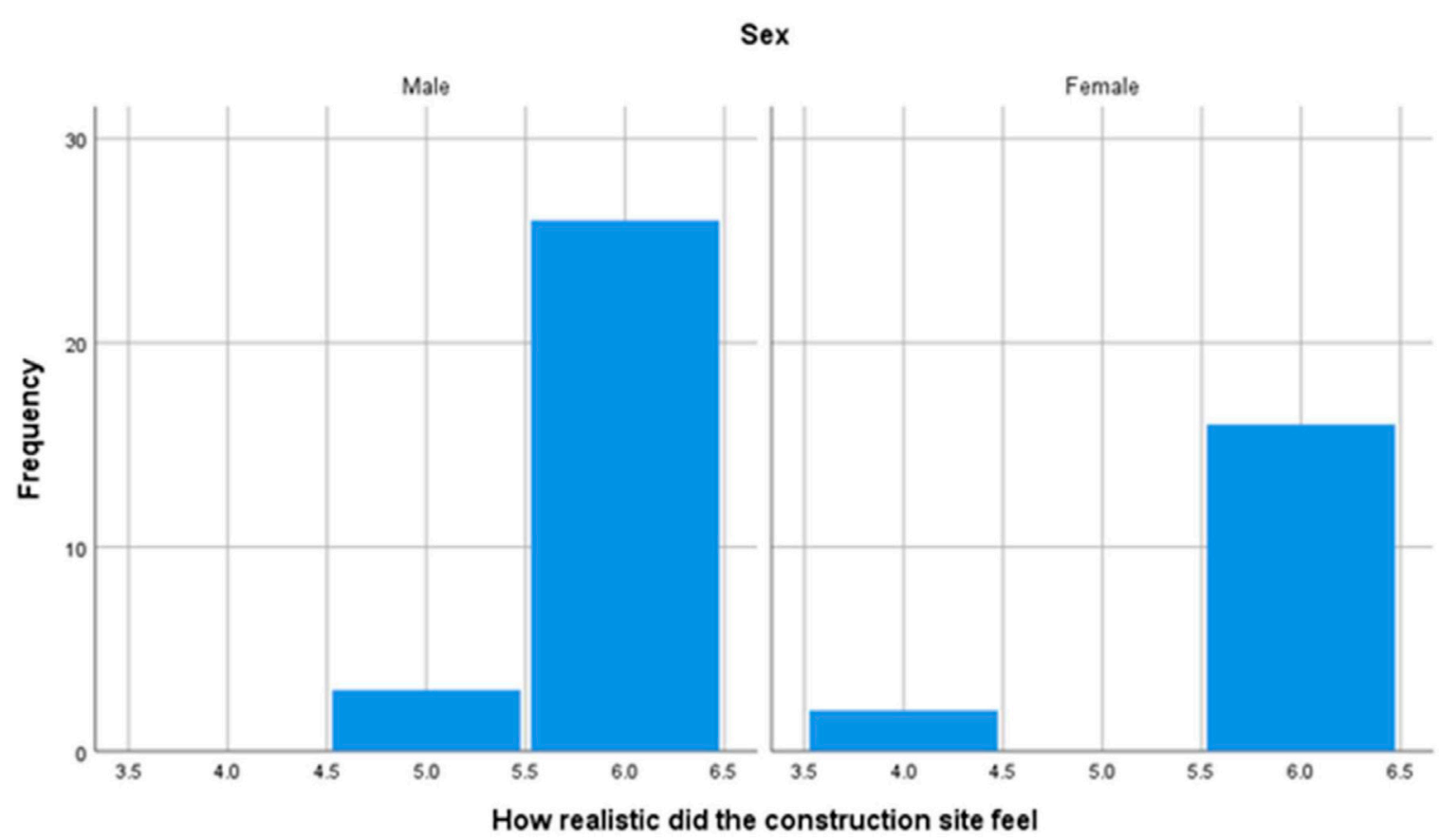

FIGURE 16 | Questionnaire participants results for how realistic the construction site felt.

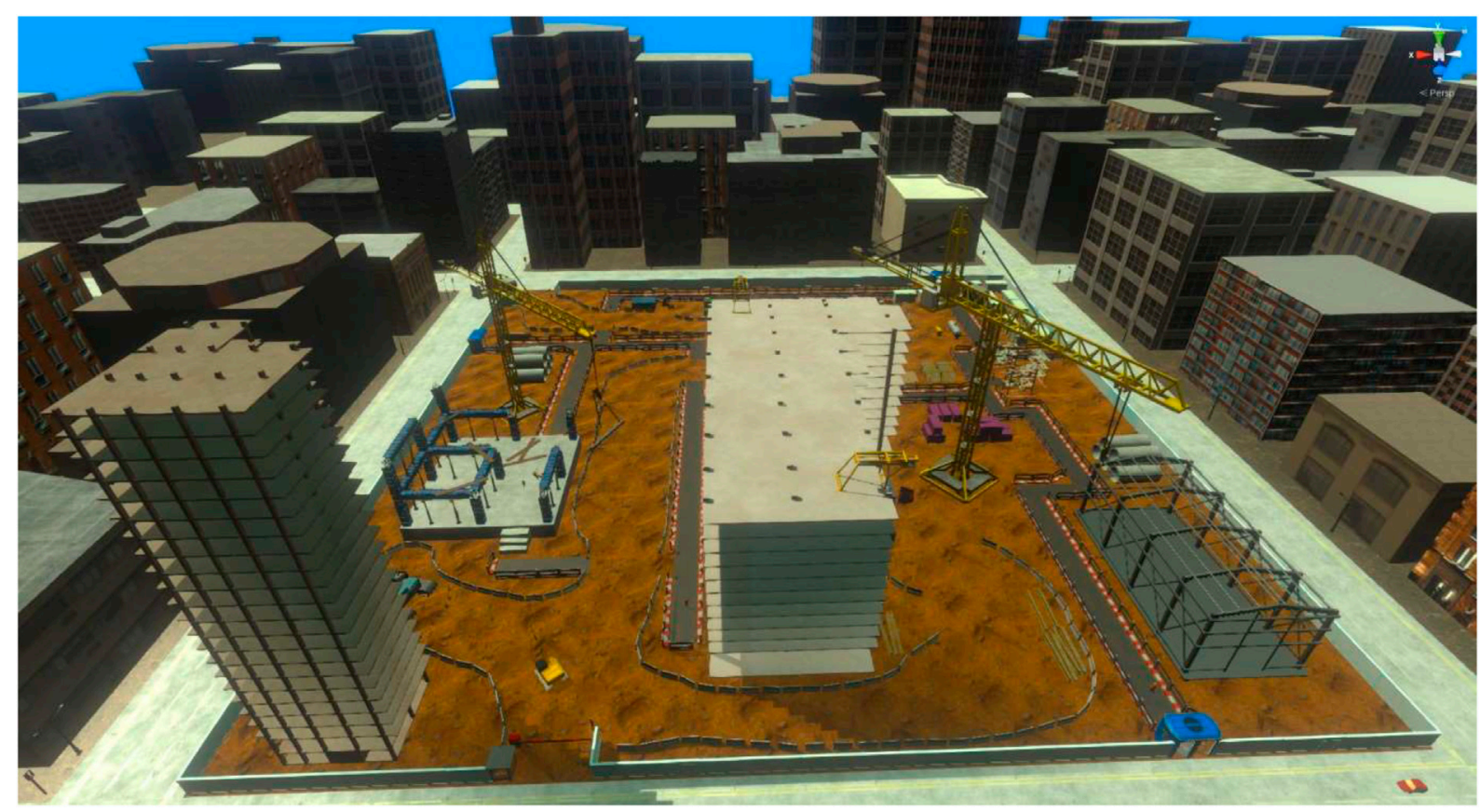

FIGURE 17 | Screenshot of the modelled construction site that is used in the game. 


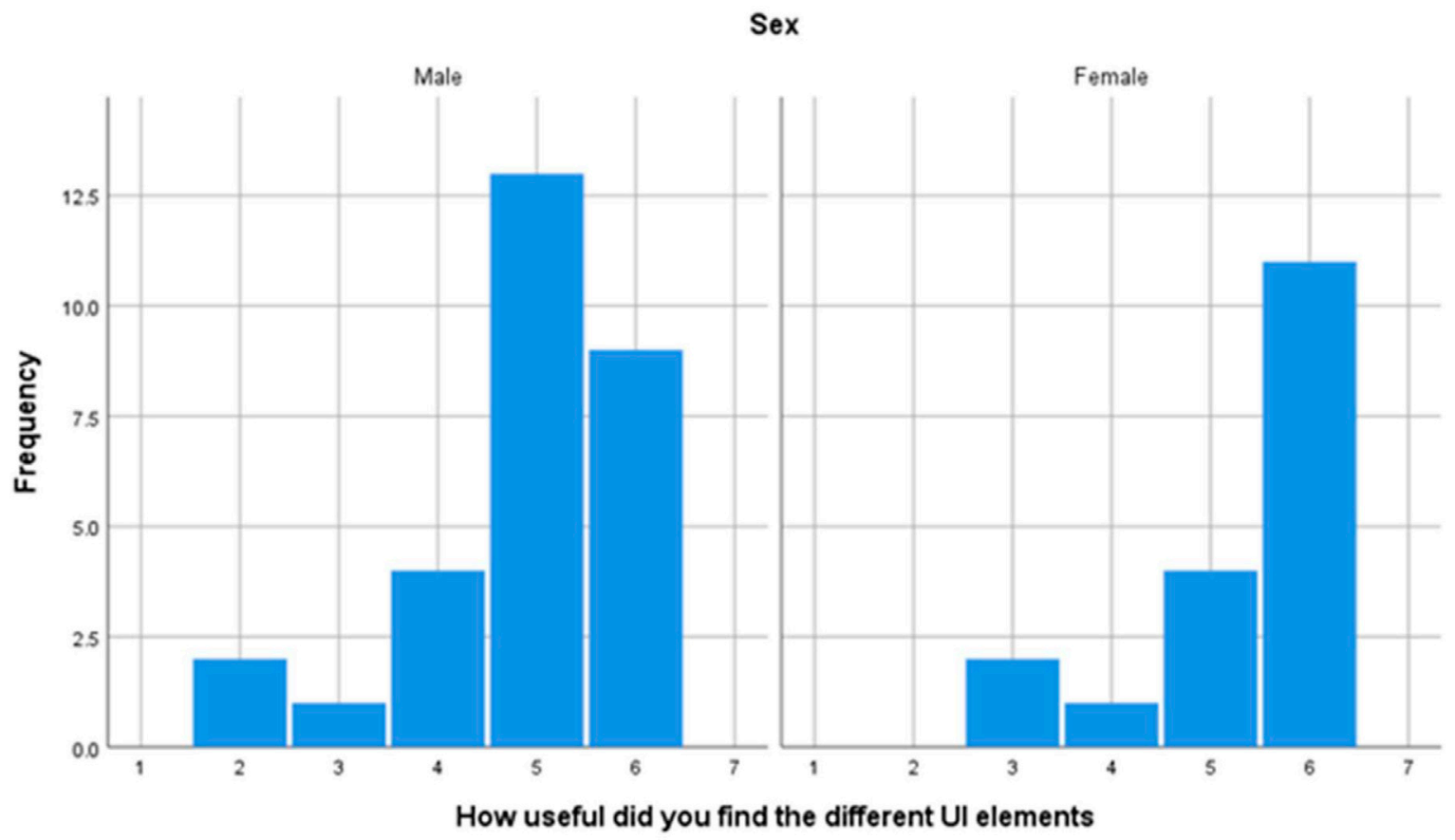

FIGURE 18 | Questionnaire participants results for how useful the onscreen user interface elements are.

\begin{tabular}{|c|c|c|c|c|c|c|c|c|}
\hline $\begin{array}{l}\text { How fun } \\
\text { did you } \\
\text { find } \\
\text { the game }\end{array}$ & $\begin{array}{l}\text { Do you } \\
\text { understand } \\
\text { the benefits } \\
\text { of using } \\
\text { drones }\end{array}$ & $\begin{array}{l}\text { How intuitive } \\
\text { did you } \\
\text { find } \\
\text { the flight } \\
\text { controls }\end{array}$ & $\begin{array}{l}\text { How easy } \\
\text { or difficult } \\
\text { did you } \\
\text { find } \\
\text { the hazard } \\
\text { minigames }\end{array}$ & $\begin{array}{l}\text { How useful } \\
\text { did you } \\
\text { find } \\
\text { the compass }\end{array}$ & $\begin{array}{l}\text { How clear } \\
\text { was your } \\
\text { objective } \\
\text { in the } \\
\text { game }\end{array}$ & $\begin{array}{l}\text { How fluid } \\
\text { did you } \\
\text { find } \\
\text { the transition }\end{array}$ & $\begin{array}{l}\text { How realistic } \\
\text { did the } \\
\text { construction } \\
\text { site } \\
\text { feel }\end{array}$ & $\begin{array}{l}\text { How useful } \\
\text { did you } \\
\text { find } \\
\text { the different } \\
\text { Ul elements }\end{array}$ \\
\hline 228.500 & 212.000 & 243.000 & 246.500 & 247.000 & 249.500 & 229.500 & 256.000 & 188.500 \\
\hline 0.453 & 0.207 & 0.625 & 0.745 & 0.741 & 0.769 & 0.438 & 0.838 & 0.090 \\
\hline
\end{tabular}

${ }^{a}$ Grouping Variable: Sex.

terms of controlling and entering the minigame while two participants suggested that they found it difficult controlling the drone and entering the minigame environment (Figure 15).

There is a consensus that construction sites are busy, inaccessible and with areas that are hard-to-reach, unsafe and a hazardous environment, and the site layout changes rapidly as work progresses. Therefore, the virtual construction site was designed to reflect and integrate these features so that flying the drone over the site can be used to capture site safety and operations activities; inspect and monitor site progress instead of safety managers conducting manual visual observations and walkthroughs. All 47 participants unanimously agreed that the design of the drone game and virtual construction site fulfilled the requirements of a real construction site where multiple activities concurrently take place (Figure 16 and Figure 17). All the players alluded to the fact that playing the drone game on a virtual construction site indicated that a regular and more robust routine site inspection can be instantaneously conducted on a real and complex construction site. Furthermore, visual site and safety inspections can be restrictive in inaccessible areas and the adoption of drone inspection have the potential to improve the safety performance on construction sites (Gheisari and Esmaeili, 2019).

Forty-two participants indicated that the user interface (UI) elements which are defined by the complexity of the drone game was extremely useful whilst five participants did not find the different UI elements particularly useful (Figure 18). Since the design of the drone game was to make the overall gameplay simple and realistic, initiating complex interfaces can potentially disorient the players which defeats the overall purpose of the game. Therefore, the design integrated a welldefined visual hierarchy considered as a key factor in good user interface into the drone game. Due to this integration in the 
game design, the UI helped the players to easily interact, navigate, acquire vital information, and accomplish the required goals (Gheisari and Esmaeili, 2019), thus making the game more relatable.

Therefore, the drone game for the virtual construction site inspection has the capability of being adopted as an informal educational and awareness training tool before players undertake the formal test for the remote pilot drone licence issued by the UK Civil Aviation Authority International (CAA). The playtesting was beneficial in understanding how the use of drones can improve site safety, increase accuracy in identifying unsafe conditions, improve consistency of reporting, monitor site progress through real-time spotting of hazards, and improve efficiency of site operations.

\section{TESTING FOR DIFFERENCES USING THE MANN-WHITNEY $U$ TEST}

The analysis conducted using the Mann-Whitney $U$ Test was important in testing for differences between the two independent groups of participants (male and female). The test is useful for evaluating whether the ranks for the two groups differ significantly (Tabachnick and Fidell, 2007; Pallant, 2011). Table 4 show the main values that are important from the output $\mathrm{Z}$ value and the significance level, which is given as Asymp. Sig. (2-tailed). Since the sample size is larger than 30 , an approximate value for a $\mathrm{z}$-approximation test includes a correction for ties in the data (Pallant, 2011). Table 4 gives the following rounded $\mathrm{z}$ values for the distinct set of variables $(-0.75,-1.26,-0.49,-0.33,-0.33,-0.29,-0.78,-0.21,-1.70)$ with a significance level $(\mathrm{p})$ of $\mathrm{p}=(0.45,0.21,0.63,0.75,0.74,0.77$, $0.44,0.84,0.09)$. The probability values $(\mathrm{p})$ shows that there is none less than or equal to 0.05 , so the results are not significant. Therefore, there is no statistically significant difference in the fun, understanding, intuition, ease, compass, clarity, fluidity, realism and usefulness scores of males and females that participated in playing the drone game for site inspection. That means gender does not have an impact on how the drone game is perceived by the players neither does it play any role in the outcome of the game play.

Furthermore, to calculate the effect size statistics, the study adopted the value of $\mathrm{z}$ that is reported in the output to calculate the approximate value of $r$.

$$
\mathrm{r}=\mathrm{z} \text { /square root of } \mathrm{N}
$$

where $\mathrm{N}=$ total number of cases.

The calculations of the effect size using Cohen (1988) criteria means the value of " $r$ " and the effect size would be considered as follows: $0.1=$ small effect, $0.3=$ medium effect, and $0.5=$ large effect. The output from the Mann-Whitney $U$ Test revealed that there is no significant difference in the variables for male and female participants. The approximate " $r$ " value calculated for each of the variable indicated a minimum value of 0.03 (very small effect) to a maximum value of 0.25 (small effect) based on the calculation of the effect size statistics.

\section{CONCLUSION}

The drone game for virtual construction site safety inspection reinforces the interactions between the players and the systems through the sensations and emotions provided by the gameplay. The minigame was another way of introducing players into the goal of the game and its story to improve first-time user experience. This study demonstrates the usefulness of virtual simulation to help improve the adoption of drone technology for site inspections. With the slow adoption of digital technology in the construction industry compared to other sectors, the work presented in this paper shows how this particular type of technology can be adopted and consequently accelerate skills development and training that can eventually make real-world drone use for site inspections more pervasive, thereby improving management of site hazards and reducing injuries and harm. The drone game acts as a "stepping stone" or "enabler" to allow drone pilots to learn about construction occupational safety and health (OSH) hazards, and for construction/ $\mathrm{OSH}$ practitioners to acquire drone flying skills so that the benefits of drone technology can be gained to reduce construction site incidents. Although the use of drones can simplify safety inspections, it however takes away the human interaction associated with site walk-around by the construction or safety managers, thus having a direct impact on workforce engagement. In the fullness of time, Artificial intelligence (AI) might probably take over this task, but this may be many years in the future and this work shows that the benefits of drone technology can be realised in the short to medium term if this game was to be developed for e.g., The Construction Industry Training Board (CITB) to incorporate into a training course. Also, there are ethical challenges regarding the deployment of drone technology on construction sites regarding privacy of workers and issues of data protection and usage. The use of real drones in a complex site could potentially increase efficiency as the data captured can provide real-time information of the site conditions while autonomously inspecting the site very quickly. The adoption of drone technology for construction site inspections has the potential to also improve quality control in terms of using the drone to monitor design specifications during the construction phase of a project. The cognitive skills acquired from playing the educational drone game for site inspection and monitoring can be successfully applied when flying a real drone for monitoring or inspecting a multipurpose or complex construction site. The game offers the player a realistic level of understanding of the mechanics of flying a drone on site. The game also creates high level of awareness, confidence and improved skill that can augment the skill required to secure the remote pilot drone licence issued by the UK CAA. The biggest challenge however was designing the game for specific audience that are potentially non-game players so that the game is easy to learn, engaging, intuitive, and truly immersive.

\section{LIMITATIONS}

Further testing in the future with more diverse population will aim at collecting other demographic factors that could be tested e.g., age, experience, discipline/occupation etc. which is a shortfall for the restrictive statistical analysis that is permissible for this 
current study. Another limitation is the complexity of deploying the specification of drone (quadcopter) used for the virtual simulation for live drone inspection and monitoring of inside buildings or enclosed areas as they will be susceptible to crash easily and struggle to detect the unsafe condition/act of workers.

\section{A Reflection on the Drone Game Design}

The end-product of the drone game had its own difficulties during play testing with some of the participants indicating that they were unable to easily identify the hazards properly even though the minigame tutorial was noticeably clear and concise. Some participants indicated that playing the game brought issues of construction health and safety challenges to limelight and that using the drone for site inspection brought about the awareness of site hazards. The design of the game incorporated a live construction site sound design giving it a realistic ambience to help make the virtual construction site feel real without making the game boring and monotonous. Overall, the players alluded that it made the game engaging giving it an accurate depiction of a construction site thus helping the player to be immersed in the game. However, some players felt that the repetitiveness of the sounds felt intrusive. The loading of the game which is dependent on the available broadband speed could result in lagging without a good broadband. However, the participants suggested that the game ran smoothly at a decent framerate for WebGL using any of the popular web browsers. The players indicated that flying the drone and the movement was fun; and the construction site models and textures with the background animations and fluidity of the drone animation were of a high

\section{REFERENCES}

Ackerman, P. L. (1988). Determinants of Individual Differences during Skill Acquisition: Cognitive Abilities and Information Processing. J. Exp. Psychol. Gen. 117, 288-318. doi:10.1037/0096-3445.117.3.288

Agapiou, A. (2021). Drones in Construction: An International Review of the Legal and Regulatory Landscape. Proc. Inst. Civil Eng. - Manag. Procurement L. 174, 118-125. doi:10.1680/jmapl.19.00041

Cameron, I., Hare, B., and Duff, R. (2007). Superior Safety Performance: OSH Personnel and Safety Performance in Construction. Leicestershire, UK: IOSH Research Report.

Cohen, J. W. (1988). Statistical Power Analysis for the Behavioural Sciences. 2nd ed. Hillsdale, NJ: Lawrence Erlbaum Associates.

Endsley, M. R., Bolté, B., and Jones, D. G. (2003). Designing for Situation Awareness: An Approach to User-Centered Design. Taylor \& Francis.

Finn, R. L., and Wright, D. (2012). Unmanned Aircraft Systems: Surveillance, Ethics and Privacy in Civil Applications. Comp. L. Security Rev. 28 (2), 184-194. doi:10.1016/j.clsr.2012.01.005

Fullerton, C. E., Allread, B. S., and Teizer, J. (2009). "Pro-active Real-Time Personnel Warning System," in Proc., Construction Research Congress (Seattle: ASCE), 31-40. doi:10.1061/41020(339)4

Gheisari, M., and Esmaeili, B. (2019). Applications and Requirements of Unmanned Aerial Systems (UASs) for Construction Safety. Saf. Sci. 118, 230-240. doi:10.1016/j.ssci.2019.05.015

Goodman, J. (2017). A New Use for Drones: On-Site Safety. Available from: http://www. builderonline.com/building/building-science/a-new-use-for-drones-on-site-safety_oi.

Hallowell, M. R., Teizer, J., and Blaney, W. (2010). Application of Sensing Technology to Safety Management. ASCE Conf. Proc. 373, 4. doi:10.1061/ 41109(373)4 standard. Other aspects that need to be considered in future designs are the controls, issues related to motion blur, flexibility to angle the first-person camera up or down in first-person mode, and increasing the demo time to properly allow players to learn about construction site hazards. Overall, the players considered the drone game for virtual construction site inspection to have some good potential and could be a fun and interesting way to educate players about construction projects, inspections, and hazards on site.

\section{DATA AVAILABILITY STATEMENT}

The original contributions presented in the study are included in the article/Supplementary Material, further inquiries can be directed to the corresponding author.

\section{ETHICS STATEMENT}

This study was approved by the School of Computing, Engineering and Built Environment Ethics Committee for the non-invasive research involving human participants.

\section{AUTHOR CONTRIBUTIONS}

All authors listed have made a substantial, direct, and intellectual contribution to the work and approved it for publication.

Han, K., Lin, J., and Golparvar-Fard, M. (2015). “A Formalism for Utilization of Autonomous Vision-Based Systems and Integrated Project Models for Construction Progress Monitoring," in Proc., 2015 Conference on Autonomous and Robotic Construction of Infrastructure (IEEE).

Homann, R., and McAllister, I. (2018). Use of Unmanned Aerial Systems Reduces HES Risks. Calgary, AB, Canada: Society of Petroleum Engineers.

HSE (2020). Construction Statistics in Great Britain, 2020. Available from: https:// www.hse.gov.uk/statistics/industry/construction.pdf.

HSE (2021). Workplace Fatal Injuries in Great Britain, 2021. Available from: https://www.hse.gov.uk/statistics/pdf/fatalinjuries.pdf.

Irizarry, J., and Costa, D. (2016). Exploratory Study of Potential Applications of Unmanned Aerial Systems for Construction Management Tasks. J. Manag. Eng. 32 (3), 1-10. doi:10.1061/(ASCE)ME.1943-5479.0000422

Irizarry, J., Gheisari, M., and Walker, B. N. (2012). Usability Assessment of Drone Technology as Safety Inspection Tools. Itcon J. Inform. Technol. Construct. 17, 194-212.

Keith, C. (2010). Agile Game Development with Scrum. Boston, MA: United States of America: Pearson Education.

Lawani, K., Hare, B., and Cameron, I. (2019). Evaluating Workplace Trust as a Construct of Worker Engagement in Construction. Proc. Inst. Civil Eng. Manag. Procurement L. 172 (3), 125-134. doi:10.1680/jmapl.18.00034

Lawani, K., Hare, B., and Cameron, I. (2018). Integrating Early Refresher Practice in Height Safety and rescue Training. Saf. Sci. 110 (A), 411-417. doi:10.1016/j. ssci.2018.03.029

Li, Y., and Liu, C. (2019). Applications of Multirotor Drone Technologies in Construction Management. Int. J. Construction Manag. 19 (5), 401-412. doi:10. 1080/15623599.2018.1452101

Macrina, G., Di Puglia Pugliese, L., Guerriero, F., and Laporte, G. (2020). Droneaided Routing: A Literature Review. Transportation Res. C: Emerging Tech. 120, 102762. doi:10.1016/j.trc.2020.102762 
Osunsanmi, T. O., Aigbavboa, C. O., Emmanuel Oke, A., and Liphadzi, M. (2020). Appraisal of Stakeholders' Willingness to Adopt Construction 4.0 Technologies for Construction Projects. Bepam 10 (4), 547-565. doi:10.1108/BEPAM-122018-0159

Pagulayan, R. J., Steury, K. R., Fulton, B., and Romero, R. L. (2018). “Designing for Fun: User-Testing Case Studies," in Funology 2. Human-Computer Interaction Series. Editors M. Blythe and A. Monk (Cham: Springer), 419-433. doi:10.1007/ 978-3-319-68213-6_27

Pallant, J. (2011). SPSS Survival Manual: A Step by Step Guide to Data Analysis Using SPSS. 4th ed. New South Wales: Allen \& Unwin.

Przybyłek, A., and Kotecka, D. (2017). Making Agile Retrospectives More Awesome. Prague, Czech Republic: Federated Conference on Computer Science and Information Systems (FedCSIS), 1211-1216. doi:10.15439/2017F423

Przybylski, A. K., Rigby, C. S., and Ryan, R. M. (2010). A Motivational Model of Video Game Engagement. Rev. Gen. Psychol. 14 (2), 154-166. doi:10.1037/ a0019440

Roca, D., Lagüela, S., Díaz-Vilariño, L., Armesto, J., and Arias, P. (2013). Low-cost Aerial Unit for Outdoor Inspection of Building Façades. Automation in Construction 36, 128-135. doi:10.1016/j.autcon.2013.08.020

Scrum.org (2021). What Is Scrum? [online]. Available from: https://www.scrum. org/resources/what-is-scrum/.

Shahmoradi, J., Talebi, E., Roghanchi, P., and Hassanalian, M. (2020). A Comprehensive Review of Applications of Drone Technology in the Mining Industry. Drones 4 (3), 34. doi:10.3390/drones 4030034

Siebert, S., and Teizer, J. (2014). Mobile 3D Mapping for Surveying Earthwork Projects Using an Unmanned Aerial Vehicle (UAV) System. Automation in Construction 41, 1-14. doi:10.1016/j.autcon.2014.01.004

Tabachnick, B. G., and Fidell, L. S. (2007). Using Multivariate Statistics. 5th ed. Boston: Pearson Education, Inc.

Tantum, M. C., and Liu, J. (2017). Unmanned Aircraft System Applications in Construction. Proced. Eng 196, 167-175.

Tkáč, M., and Mésároš, P. (2019). Utilizing Drone Technology in the Civil Engineering. Selected Scientific Pap. - J. Civil Eng. 14 (Issue 1), 27-37. doi:10.1515/sspjce-2019-0003
Toole, T. M. (2002). Construction Site Safety Roles. J. Constr. Eng. Manage. 128 (3), 203-210. doi:10.1061/(asce)0733-9364(2002)128:3(203)

Wen, M. C., and Kang, S. C. (2014). “Augmented Reality and Unmanned Aerial Vehicle Assist in Construction Management," in Proc., Computing in Civil and Building Engineering (IEEE), 1570-1577. doi:10.1061/ 9780784413616.195

Xiang, T. Z., Xia, G. S., and Zhang, L. (2019). Mini-UAV-based Remote Sensing: Techniques, Applications and Prospectives. IEEE Geosci. Remote Sensing Magaz. 7 (3), 29-63. doi:10.1109/MGRS.2019.2918840

Zhou, H., Wang, H., and Zeng, W. (2018a). Smart Construction Site in Mega Construction Projects: A Case Study on Island Tunneling Project of Hong Kong-Zhuhai-Macao Bridge. Front. Eng. Manag. 5 (1), 78-87. doi:10.15302/ J-FEM-2018075

Zhou, Z., Irizarry, J., and Lu, Y. (2018b). A Multidimensional Framework for Unmanned Aerial System Applications in Construction Project Management. J. Manage. Eng. 34 (3), 04018004. doi:10.1061/(ASCE)ME.1943-5479.0000597

Conflict of Interest: The authors declare that the research was conducted in the absence of any commercial or financial relationships that could be construed as a potential conflict of interest.

Publisher's Note: All claims expressed in this article are solely those of the authors and do not necessarily represent those of their affiliated organizations, or those of the publisher, the editors and the reviewers. Any product that may be evaluated in this article, or claim that may be made by its manufacturer, is not guaranteed or endorsed by the publisher.

Copyright (C) 2022 Lawani, Hare, Cameron, Homatash and Campbell. This is an open-access article distributed under the terms of the Creative Commons Attribution License (CC BY). The use, distribution or reproduction in other forums is permitted, provided the original author(s) and the copyright owner(s) are credited and that the original publication in this journal is cited, in accordance with accepted academic practice. No use, distribution or reproduction is permitted which does not comply with these terms. 